\title{
Spillover Effects of Institutions on Cooperative Behavior, Preferences, and Beliefs
}

Citation for published version (APA):

Engl, F., Riedl, A., \& Weber, R. A. (2017). Spillover Effects of Institutions on Cooperative Behavior, Preferences, and Beliefs. Maastricht University, Graduate School of Business and Economics. GSBE Research Memoranda No. 016 https://doi.org/10.26481/umagsb.2017016

Document status and date:

Published: 13/06/2017

DOI:

10.26481/umagsb.2017016

Document Version:

Publisher's PDF, also known as Version of record

\section{Please check the document version of this publication:}

- A submitted manuscript is the version of the article upon submission and before peer-review. There can be important differences between the submitted version and the official published version of record.

People interested in the research are advised to contact the author for the final version of the publication, or visit the DOI to the publisher's website.

- The final author version and the galley proof are versions of the publication after peer review.

- The final published version features the final layout of the paper including the volume, issue and page numbers.

Link to publication

\footnotetext{
General rights rights.

- You may freely distribute the URL identifying the publication in the public portal. please follow below link for the End User Agreement:

www.umlib.nl/taverne-license

Take down policy

If you believe that this document breaches copyright please contact us at:

repository@maastrichtuniversity.nl

providing details and we will investigate your claim.
}

Copyright and moral rights for the publications made accessible in the public portal are retained by the authors and/or other copyright owners and it is a condition of accessing publications that users recognise and abide by the legal requirements associated with these

- Users may download and print one copy of any publication from the public portal for the purpose of private study or research.

- You may not further distribute the material or use it for any profit-making activity or commercial gain

If the publication is distributed under the terms of Article $25 \mathrm{fa}$ of the Dutch Copyright Act, indicated by the "Taverne" license above, 
Florian Engl, Arno Riedl,

Roberto A. Weber

Spillover Effects of Institutions on Cooperative Behavior, Preferences, and Beliefs

$\mathrm{RM} / 17 / 016$

\section{GSBE}

Maastricht University School of Business and Economics

Graduate School of Business and Economics

P.O Box 616

NL-6200 MD Maastricht

The Netherlands 


\title{
Spillover Effects of Institutions on Cooperative Behavior, Preferences, and Beliefs*
}

\author{
Florian Engl \\ University of Cologne
}

\author{
Arno Riedl \\ Maastricht University
}

\author{
Roberto A. Weber \\ University of Zurich
}

May 2017

\begin{abstract}
Institutions are an important means for fostering prosocial behaviors, but in many contexts their scope is limited and they govern only a subset of all socially desirable acts. We use a laboratory experiment to study how the presence and nature of an institution that enforces prosocial behavior in one domain affects behavior in another domain and whether it also alters prosocial preferences and beliefs about others' behavior. Groups play two identical public good games. We vary whether, for only one game, there is an institution enforcing cooperation and vary also whether the institution is imposed exogenously or arises endogenously through voting. Our results show that the presence of an institution in one game generally enhances cooperation in the other game thus documenting a positive spillover effect. These spillover effects are economically substantial amounting up to 30 to 40 percent of the direct effect of institutions. When the institution is determined endogenously spillover effects get stronger over time, whereas they do not show a trend when it is imposed exogenously. Additional treatments indicate that the main driver of this result is not the endogeneity but the temporal trend of the implemented institution. We also find that institutions of either type enhance prosocial preferences and beliefs about others' prosocial behavior, even toward strangers, suggesting that both factors are drivers of the observed spillover effects.
\end{abstract}

Keywords: Public goods, institutions, spillover effect, social preferences, beliefs JEL Classification Codes: C92, D02, D72, H41

*Engl: University of Cologne, Faculty of Management, Economics, and Social Sciences, Germany; email: florian.engl@uni-koeln.de, phone: +49 221470 1845. Riedl: CESifo, IZA, Netspar \& Maastricht University, Department of Economics (AE1), P.O. Box 616, 6200 MD Maastricht, The Netherlands; email: a.riedl@maastrichtuniversity.nl, phone: +31 4338 84982. Weber: University of Zürich, Department of Economics, Blümlisalpstrasse 10, CH-8006 Zürich, Switzerland; email: roberto.weber@econ.uzh.ch, phone: +41 4463436 88. We thank Pedro Dal Bo, Guillaume Fréchette, Bernd Irlenbusch, Martin Kocher, and Bertil Tungodden for valuable discussions and participants at several seminars and conferences for helpful comments. 


\section{Introduction}

The success of any society is largely determined by the formal and informal institutions (e.g., laws and norms) that govern their members' behavior (North, 1990; Ostrom, 1990). These institutions are often in place to overcome social dilemmas, in which individual members' incentives are not aligned with what is best for the society at large. Examples of social dilemmas include public goods provision, environmental protection and tax compliance.

An important aspect of most institutions is that they are limited in scope, in the sense that they cannot enforce desired behavior beyond their limits. It is however possible that institutions exhibit spillover effects and therefore indirectly affect behavior in areas where they do not directly apply. Hence, the overall effectiveness of an institution for fomenting socially beneficial behavior depends not only on how it encourages those behaviors that are subject to the institution, but also on how it affects those behaviors beyond its scope.

For example, in tax enforcement, some sources of income or wealth are quite easily monitored - and therefore subject to the relevant enforcement institutions - whereas for other forms of income the tax authority has to rely largely on voluntary reporting. In environmental domains, some measures by governments (e.g., energy saving through regulation) directly restrict consumers' choices while changes in other domains (e.g., littering behavior) are more difficult to enforce. In organizational contexts, managers can enforce cooperation among team members in tasks that are easily monitored (e.g. a specific teaching load for faculty of an academic department) but cannot similarly control cooperative behavior in other domains, such as "good citizenship." Therefore, understanding the extent to which institutions foster or deter people's voluntary compliance with rules in domains beyond the scope of institutions is important for positive economics and policy.

In this paper, we use laboratory experiments to study whether enforcement of prosocial behaviors by an institution in one domain spills over to another domain that is ungoverned by any institution.1. More precisely, we conducted laboratory experiments in which subjects simultaneously play two linear public goods games, within fixed fourperson groups, repeatedly for 20 periods. In each period and in each of the two games, every group member has an endowment of 20 , which can be contributed to the group. Contributions are doubled and then redistributed among all four group members.

In a baseline "no institution" treatment, behavior is not governed by any enforcement mechanism in either game. That is, subjects can freely choose their contribution to the public goods and free-riding in both games is a dominant strategy for narrowly selfish agents. In the other two treatments, one of the two games is monitored by an institution ("PGG Rule"), while the other is not ("PGG No Rule"). The specific institution in our experiment corresponds to a central authority that punishes subjects who contribute less than a specified amount, the Minimum Contribution Requirement (MCR), with forfeiture of all income in that period from the respective game.

\footnotetext{
${ }^{1}$ We use experiments because this allows us make causal statements about spillover effects of institutions. For correlational evidence of a relationship between institutions and pro-social behaviors, see Herrmann, Thöni, and Gächter (2008); Henrich, Boyd, Bowles, Camerer, Fehr, McElreath, and Gintis (2001); Fisman and Miguel (2007).
} 
Whether spillovers of institutions exist and how strong they eventually are may depend on the origin of the institution. For example, it has been found that democratically chosen institutions are more effective in fostering cooperation than exogenously imposed ones (Dal Bó, Foster, and Putterman, 2010; Kamei, 2016, Sutter, Haigner, and Kocher, 2010, Tyran and Feld, 2006). By extension, this may also hold for spillovers of institutions. We therefore implement treatments in which we vary the origin of the institution. In the "exogenous institution" treatment, the $M C R$ in "PGG Rule" is exogenously imposed and set to the full endowment of 20. In the "endogenous institution" treatment, the $M C R$ is determined by the following voting mechanism: each group member submits a vote for a desired $M C R$ level, between 0 and 20, and the implemented $M C R$ in a group is the minimal number voted for by any member. Hence, the endogenous institution arises through unanimous approval of a $M C R$ level, with all group members voting for at least that level of enforced contributions 2

In our analysis, we distinguish between the direct effects of an institution and spillover effects. The former refer to the change in contributions brought about by the institution in the game where it applies ("PGG Rule"). The latter refer to the change in contributions brought about by the institution in the game where it does not apply ("PGG No Rule"). Both are measured relative to contributions observed in the "no institution" treatment.

In addition to spillover effects, we are also interested in whether the existence of an enforcement institution in "PGG Rule" affects, separately, preferences and beliefs. This provides insights into possible mechanisms underlying spillover effects. Thus, in all three treatments we measure preferences for conditional cooperation and beliefs about others' cooperation using a one-shot strategy method public goods game. We elicit these measures at three points in time and with respect to different reference groups. First, right before the 20 periods of the public goods games described above, we elicit subjects' initial cooperation preferences and beliefs about other subjects' cooperation, using randomly chosen subjects as the reference group. Second, immediately after these 20 periods, preferences and beliefs are measured with respect to the "partners" with whom subjects have just interacted. Thereafter, preferences and beliefs are elicited once more with respect to an unfamiliar group of "strangers".

Our main results can be summarized as follows. Both the "exogenous institution" treatment and "endogenous institution" treatment exhibit significantly positive direct effects; that is, both types of institutions strongly increase cooperation in the game where they apply, meaning that they work as intended. Both institutions also induce significantly positive spillover effects. These spillover effects are economically substantial, comparable in magnitude to roughly 30 to 40 percent of the direct effects. Together, the direct and indirect effects lead to a substantial increase in welfare relative to the treatment without an institution. On average, the spillover effects in both treatments with an institution are similar, but they significantly differ in their dynamics. The spillover effects from the endogenously adopted institution increase over time, whereas the spillover effects from the exogenously imposed institution show no trend.

\footnotetext{
${ }^{2}$ Moreover, the unique strict subgame-perfect Nash equilibrium in the voting stage is to select the same institution as the one exogenously imposed in our other treatment, with the $M C R$ of full contributions.
} 
With respect to conditional cooperation preferences and beliefs about others' contributions we see a clear effect of the presence of an institution. In comparison to the "no institution" treatment, in both treatments with an institution, beliefs about others' contributions are higher and preferences for conditional cooperation are stronger, even after the institution ceases to exist. This result extends to strangers, with whom there was no prior interaction. This suggests that the observed spillover effects are due to institutions impacting both subjects' own preferences for cooperation and their beliefs about others' cooperativeness. To the best of our knowledge, this is the first clean evidence on the causal effect of institutions on intrinsic preferences for cooperation.

To gain further insight into possible reasons for the different dynamics of spillover effects between the exogenously imposed and endogenously adopted institutions, we conducted two further treatments. In the "endogenous 0-20 institution" treatment we use a voting mechanism that facilitates the endogenous implementation of strong institutions (a $M C R$ of 20) from the very beginning. We achieve this by weakening the unanimity requirement and letting group members only vote for a $M C R$ of either 0 or 20 points - i.e., either no requirement or a requirement to contribute the full endowment. This allows for a better comparison to the "exogenous institution" treatment, where the $M C R$ of 20 is exogenously implemented throughout. Further, we conducted an "exogenous yoked institution" treatment, which exogenously implemented, in each period, the same $M C R$ that was selected, on average, in the "endogenous institution" treatment. Thus, if in a given period of the "endogenous institution" treatment the average $M C R$ was 10, then this amount was exogenously imposed as the $M C R$ in the same period of the "exogenous yoked institution" treatment. This treatment allows us to identify whether it is the endogeneity of the $M C R$ that matters for the relatively stronger spillover effect over time observed in the "endogenous institution" treatment, or whether it is the temporal trend of the $M C R$ levels selected in this treatment.

The results of these additional treatments strongly suggest that it is the increasing trend of the $M C R$, rather than the endogenous adoption, that yields increasing spillover effects. In the "endogenous 0-20 institution" treatment, we observe modest and stable spillover effects, which do not increase over time despite the endogeneity of the institution. However, in the "exogenous yoked institution" treatment the spillover effects increase over time and are statistically indistinguishable from the spillover effects in the "endogenous institution" treatment.

The rest of the paper is organized as follows. Section 2 summarizes the related literature and develops hypotheses regarding the effect of institutions on behavior beyond their immediate range. Section 3 introduces the experimental design and two main treatments and Section 4 presents the results. Section 5 introduces and presents the results of the two additional treatments. In Section 6 we discuss possible explanations for our findings and Section 7 concludes and discusses directions for future research. 


\section{Related literature and hypotheses}

Prior experimental research in economics demonstrates the effectiveness of institutions for enforcing high cooperation levels in social dilemma situations (see, e.g., Ostrom, Walker, and Gardner, 1992; Gächter and Fehr, 2000, for exogenously imposed institutions, and, e.g., Gürerk, Irlenbusch, and Rockenbach, 2006, Kosfeld, Okada, and Riedl, 2009, for endogenously adopted institiutions). These institutions typically work by changing the monetary incentives for non-cooperative behavior by making it more costly relative to cooperative behavior.

However, this strand of literature ignores potential spillover effects of institutions. Our main interest is precisely in how the presence of an effective institution in one domain potentially extends to domains not governed by the institution. We start from the null hypothesis that there will be no spillover effects. This null hypothesis is supported under the standard preferences framework of narrow selfishness, whereby selfish players follow their dominant strategy and contribute zero in "PGG No Rule" independent of the presence or the type of the institution that governs "PGG Rule" [3 The null hypothesis is also supported irrespective of the specific preference type (e.g., other-regarding preferences) whenever subjects engage in narrow framing and ignore the presence of another game when making decisions in one game.

Importantly, a number of studies suggest the possibility of spillovers across contexts and, therefore, that the presence of an institution in one context might affect behavior elsewhere. For example, a few papers show that having subjects simultaneously play multiple games can lead them to adopt different strategies than when the game are played independently (Bednar, Chen, Liu, and Page, 2012, Savikhin and Sheremeta, 2013). 4 There is also evidence that splitting one public goods game into two simultaneously played games increases subject's contributions (Bernasconi, Corazzini, Kube, and Maréchal, 2009). In the case of sequentially played games, studies show that groups that manage to sustain high efficiency levels in a weakest-link game have higher cooperation rates in subsequently played prisoner's dilemma games (Knez and Camerer, 2000), that there are learning spillovers between strategically similar games (Grimm and Mengel, 2012), and that there exist only very modest spillovers between competitive and cooperative games that are played with the same opponents (Cason and Gangadharan, 2013). Furthermore, Cason, Savikhin, and Sheremeta (2012) find behavioral spillovers between minimum- and median-effort coordination games when they are played sequentially, but not when they are played simultaneously. Importantly, none of these studies investigates spillover effects of institutions. Due to the very different nature of these studies the results do not give a clear indication whether such spillover effects will exist and how they may look like.

A separate line of research argues that institutional features can create a crowding out or crowding in of intrinsic motivations (for survey articles, see Frey and Jegen, 2001;

\footnotetext{
${ }^{3}$ For a detailed summary of the theoretical predictions of standard preferences, see Appendix A.1

${ }^{4}$ Relatedly, McCarter, Samek, and Sheremeta (2014) find that pro-social behavior is stronger when two simultaneously played public goods games are played with different groups than when they are played with identical groups and Falk, Fischbacher, and Gächter (2013) report a small behavioral spillover between two public goods games when played in overlapping neighborhoods.
} 
Gneezy, Meier, and Rey-Biel, 2011; Bowles and Polanía-Reyes, 2012).If institutions affect intrinsic preferences, this change may spill over and influence a person's behavior even in domains in which the institution is not active (Frey, 1993). For example, exogenous control of one's behavior may compromise a sense of authority, thereby leading to resistance against the behaviors an institution is attempting to foment (Deci, 1975, Deci and Ryan, 1985; Deci, Koestner, and Ryan, 1999; Belot and Schröder, 2016). While such resistance is not possible in domains that are regulated by the institution, it can manifest itself in domains beyond the scope of the institution. This also implies that an endogenously chosen institution, whereby no exogenous control is exerted on a group, might diminish the degree of crowding out.

On the other hand, institutions may also increase people's intrinsic willingness to act prosocially. For example, individuals may be motivated by a desire to follow social norms (Elster, 1989, López-Pérez, 2008, Krupka and Weber, 2013). Peysakhovich and Rand (2016) demonstrate that behavioral norms can be shaped by experience. They show that creating either a "defection norm" or a "cooperation norm" in prisoners' dilemma games differentially affects the tendency to punish uncooperative behaviors in subsequent games. In a similar vein, d'Adda, Capraro, and Tavoni (2017) provide evidence that some policies affect behavior even after they have been faded out. For our treatments, this evidence suggests that the imposition of a positive $M C R$ in one game ("PGG Rule") may signal a social norm, which subjects may prefer to comply with even in the unregulated game ("PGG No Rule"). This implies that we should observe positive spillover effects. These effects may be stronger in the "endogenous institution" treatment where the $M C R$ is implemented by a unanimous voting process, thus creating a stronger norm.

An institution may also affect cooperative behavior in the unregulated "PGG No Rule" through an effect on beliefs about others' cooperativeness. In public goods games, many people act as conditional cooperators, i.e., they reciprocate positively to their beliefs about others' contributions (Fischbacher, Gächter, and Fehr, 2001; Fehr and Fischbacher, 2004; Fischbacher and Gächter, 2010). Therefore, if institutions directly change beliefs about others' cooperativeness, this would provide a channel through which cooperative behavior is affected even beyond the scope of the institution (Jehiel, 2005, Sliwka, 2007; Benabou and Tirole, 2011). Observing votes for a high $M C R$ in the "endogenous institution" treatment, or high contributions in either treatment, might lead subjects to believe that cooperation is more likely to obtain in the unregulated "PGG No Rule". On the other hand, the fact that an institution is needed to support contributions in "PGG Rule" may lead to more pessimistic beliefs about contributions in "PGG No Rule". Moreover, the effect may differ between the "endogenous institution" treatment and the "exogenous institution" treatment as there is evidence that people reciprocate others' cooperation only when such cooperation is voluntary and intentional (Cettolin and Riedl, 2014). Hence, changes in beliefs may create spillover effects in either direction and they may differ across treatments.

There also exist channels other than changes in preferences or beliefs that allow for spillover effects. For example, models of pure altruism suggest that people desire given 
levels of public good provision and are indifferent whether it is provided through their own contribution or those of others. Therefore, pure altruism suggests that an institution enforcing contributions in "PGG Rule" may crowd out voluntary contributions to "PGG No Rule", one-to-one (Bernheim, 1986; Andreoni, 1988).

In sum, the existing empirical literature and several theoretical arguments suggest that institutions can have an effect on preferences for cooperation and beliefs about others' cooperativeness and that the effect might differ depending on whether the institution is exogenously imposed or endogenously adopted. However, whether these effects spill over to domains where there is no institution in place and whether eventual spillover effects are positive or negative remains open.

\section{Experimental Design}

The experiment consists of five parts. The main part (Part II) investigates the extent to which an institution that monitors and enforces cooperation in one environment spills over to an identical environment where the institution does not apply. The treatments in Part II vary the way in which the institution is implemented in order to distinguish between spillovers that are generated by endogenously adopted versus exogenously imposed institutions. Parts I, III and IV are preference and belief elicitation stages that help to identify whether institutions have persistent influence on subjects' beliefs, preferences or both. These parts are identical across all treatments. Finally, in Part V, we measure various individual characteristics. Table 1 provides an overview of the experimental design.

Table 1: Overview of experimental design

\begin{tabular}{lcc}
\hline Part I & \multicolumn{2}{c}{$\begin{array}{c}\text { Preference and belief elicitation } \\
\text { (randomly determined group) }\end{array}$} \\
\hline Part II & $\begin{array}{c}20 \text { periods of "PGG No Rule" and "PGG Rule" } \\
\text { (new group - absolute stranger matching) }\end{array}$ \\
\cline { 2 - 3 } & $\begin{array}{c}\text { No } \\
\text { institution } \text { Exogenous }\end{array}$ & $\begin{array}{c}\text { Endogenous } \\
\text { institution }\end{array}$ \\
& institution \\
\hline Part III & Preference and belief elicitation \\
& (same group as in Part II) \\
\hline Part IV & \multicolumn{2}{c}{ Preference and belief elicitation } \\
& (new group - absolute stranger matching) \\
\hline Part V & \multicolumn{2}{c}{ Individual characteristics } \\
\hline
\end{tabular}

\subsection{The Game}

We use a linear public goods game as our workhorse, whose basic structure is constant across all parts and treatments. Each of four group members $(n=4)$ is endowed with 20 points $(w=20)$ and can decide how many points to keep for him- or herself and how many to contribute to a public good. The sum of points contributed to the public good is doubled and equally distributed among all members of the group (implying a marginal per 
capita return of 0.5$)$. Thus, given the contribution of all group members $\left(\mathbf{g}=\left(g_{1}, \ldots, g_{4}\right)\right)$ the material payoff of group member $i$ in the public goods game equals

$$
\pi_{i}(\mathrm{~g})=20-g_{i}+0.5 \sum_{j=1}^{4} g_{j} .
$$

Before explaining Parts I, III, IV, and V in more detail, we describe Part II, which is the core of the experiment.

\subsection{Part II: Treatment stage}

At the beginning of Part II, subjects were randomly matched into four-person groups consisting of subjects who had not interacted previously. Within Part II, subjects played repeatedly, for 20 periods, with the same group of subjects (partner matching). Part II differs between three treatments, "no institution", "exogenous institution", and "endogenous institution."

\subsection{1 "No institution" treatment}

In each period of the "no institution" treatment, subjects simultaneously played two public good games with the same group members. The parameters of both games are as specified before. That is, in each game subjects were endowed with 20 points and were free to contribute to each public good any integer value between zero and 20 points. The two public goods games were displayed next to each other on the same computer screen. Henceforth, these games are called "PGG No Rule" and "PGG Rule" 5

Before subjects made their contribution decisions in the two public good games, they were asked to indicate, separately and in each period, their belief about the average contribution of the other three group members in the two games. To avoid hedging, belief elicitation was not incentivized monetarily, but subjects were asked to enter their best estimates 6 Thereafter, subjects made their contributions to the public goods. They entered and submitted them in the two games separately and decided themselves about the timing of their contributions to either game. Thus, one period in our experiment may be thought of resembling a period of time (e.g., a day), in which one has to fulfill certain tasks - some monitored, others not - and for which one can decide when and in what order to complete these tasks.

At the end of each period, subjects were informed about the contributions of all group members to both public goods and their payoffs from both games. Contributions were displayed in descending order and it was not possible to identify which member of the group contributed which number of points to the public goods in the two games. A subject's total payoff in each period consisted of the sum of the payoffs of the two games.

\footnotetext{
${ }^{5}$ Obviously, in the "no institution" treatment there was no "rule" in any game. In the experiment, the two games were neutrally labeled as "Task Left" and "Task Right" in all treatments.

6 Gächter and Renner (2010) find that incentivized beliefs tend to lead to higher contribution levels in repeated public goods games than either non-incentivized beliefs or no beliefs at all. In this part of the experiment we are mainly interested in behavior and, therefore, decided against incentivizing belief elicitation.
} 
At the end of the experiment, one of the 20 periods was randomly selected for payment. The total payoff in the randomly selected period was multiplied by 20 , so that it counted for all 20 periods.7

\subsection{2 "Exogenous institution" treatment}

We implemented two treatments with institutions. In both treatments, the setup of "PGG No Rule" is identical to the "no institution" treatment-i.e. subjects were free to contribute any integer amount between 0 and 20 points to the public good. The payoff structure of "PGG Rule", however, is affected by the treatments. In particular, in each period "PGG Rule" is governed by an institution that monitors the group members' contributions in that game and punishes those members that contribute less than a certain minimum contribution requirement (henceforth $M C R$ ). Specifically, the income from "PGG Rule" of any group member who contributes at least as many points to the group account as specified by the $M C R$ is unaffected by the institution, whereas any group member who contributes fewer points to the group account than the $M C R$ level forfeits any income from "PGG Rule" in that period.

In the "exogenous institution" treatment, the $M C R$ in "PGG Rule" is fixed at 20, i.e., the entire endowment for that game. In each period, subjects see the $M C R$, on their screen when making contribution decisions. The payoff from "PGG Rule" in the "exogenous institution" treatment is thus determined as follows:

$$
\pi_{i}(\mathbf{g})= \begin{cases}20-g_{i}+0.5 \cdot \sum_{j=1}^{4} g_{j} & \text { if } g_{i}=20 \\ 0 & \text { if } g_{i}<20 .\end{cases}
$$

As in the "no institution" treatment the total per-period payoff of each subject is equal to the sum of the payoffs in "PGG No Rule" and "PGG Rule".

Note that if one group member is penalized for contributing less than the $M C R$ in "PGG Rule", the incomes of the other group members are not affected. Thus, the other group members still benefit from any contributions made by any group member in "PGG Rule". This reflects, for instance, an institution that confiscates part of an individual's income as a penalty.

\subsection{3 "Endogenous institution" treatment}

The "endogenous institution" treatment consists of two stages that are repeated in every period: an institution formation stage and a contribution stage.

As in the "exogenous institution" treatment, the institution again imposes a $M C R$ on contributions only in "PGG Rule". The difference is that, now, the $M C R$ is determined endogenously in an institution formation stage. That is, instead of facing an exogenously set contribution threshold of 20, in each period each group votes to determine the $M C R$

7 Azrieli, Chambers, and Healy (2017) show that paying one randomly chosen period is incentive compatible when assuming only monotonicity. 
for that group. Each member of the group casts a vote for a desired $M C R$ by specifying an integer value between 0 and 20. Following voting, the lowest contribution threshold that was voted for by any group member is implemented as the $M C R$ for that period. We chose this particular mechanism because it imposes a unanimity requirement, in the sense that a particular $M C R$ level is adopted only if everyone voted for at least that level. Thus, the endogenously implemented $M C R$ has the support of all group members.

At the end of the institution formation stage, group members were informed about the implemented $M C R$ for that period and the votes that were cast. Votes were displayed in descending order and it was not possible to identify which member of the group voted for which $M C R$.

After subjects were informed about the $M C R$, but before they made their contribution decisions, they were asked to indicate their belief about the other group members' average contribution to the two public goods games.

The contribution stage is identical to the "exogenous institution" treatment, with the only difference that in each period the $M C R$ is now the one group members agreed upon in the institution formation stage. The payoff from "PGG Rule" in the "endogenous institution" treatment is thus determined as follows:

$$
\pi_{i}(\mathbf{g})= \begin{cases}20-g_{i}+0.5 \cdot \sum_{j=1}^{4} g_{j} & \text { if } g_{i} \geq M C R \\ 0 & \text { if } g_{i}<M C R .\end{cases}
$$

Payoffs and feedback were identical to those in the "exogenous institution" treatment, with the additional information of the realized $M C R$ in that period. The rules and procedure for payout were the same as in the other treatments.

\subsection{Part I, III \& IV: Preference and belief elicitation stages}

We elicited cooperative preferences and beliefs about others' cooperativeness at three points in the experiment (see Table 11). First, before the main task (Part I), second, immediately after the main task, with respect to the identical group from Part II (Part III) and, thereafter, third, with respect to a new group of randomly-selected participants with whom a subject had never interacted before (Part IV).

In Parts I, III and IV, subjects played a one-shot four-person linear public good game with endowments of 20 and no institution. All subjects made an unconditional decision regarding how many of their 20 points to contribute to the public good. While such unconditional contributions are informative about cooperative behavior, they are likely affected by the beliefs about how much others will contribute. Therefore, to separate beliefs and preferences, in each part there were two further stages: a belief-elicitation stage in which we elicited beliefs about how much others would unconditionally contribute in the public good game and a preference-elicitation stage in which we elicited contribution decisions conditional on others' contributions.

In the belief-elicitation stage we used the incentive compatible Most Likely Interval elicitation rule (MLI) introduced by Schlag and van der Weele (2015). Specifically, subjects 
were asked to provide two integer values as the upper and the lower bound of the range of values that they believed would contain the actual average unconditional contribution of the other three group members (rounded to the nearest integer). Subjects earned 20 if they specified a range consisting of only one number (i.e., a point prediction) and that number was equal to the actual rounded average contribution of the other group members. For each unit that the provided range increased in width, a subject's potential earnings decreased by one point. Hence, if a subject provided an interval of width 10, then the subject earned 10 if the interval contained the actual realized average. Regardless of the width of the interval provided, subjects earned nothing if the actual average contribution of others was outside the specified range. Thus, subjects were incentivized to reveal their true beliefs as precisely as possible. The width of the range they provided is a measure of uncertainty regarding their beliefs.

In the preference-elicitation stage, we employ the strategy method for eliciting conditional contribution profiles (Selten, 1967; Fischbacher, Gächter, and Fehr, 2001). After having indicated their unconditional contribution to the public good, subjects were asked to specify how much they would contribute for each of the 21 possible levels of average contribution (rounded to integers) of the other group members. This procedure elicits conditional cooperation preferences that are independent of beliefs.

After all subjects made their unconditional and conditional contribution decisions, three of the four group members were randomly selected to implement their specified unconditional contributions. For the remaining group member, the conditional contribution decision was implemented, given the rounded average of the other group members' unconditional contributions. Subjects were paid their earnings for each of Parts I, III, and IV.

\subsection{Part V: Individual characteristics}

In Part V, we collected other individual characteristics. First, we elicited cognitive ability using the Cognitive Reflection Test (Frederick, 2005) and rule-following propensity via the rule-following task introduced in Kimbrough and Vostroknutov (2016a). In the rulefollowing task, subjects saw, on their computer screen, two baskets, one yellow and one blue, and a ball. They were told that they would earn 2 ECU if they placed the ball in the yellow basket and $1 \mathrm{ECU}$ if they placed the ball in the blue basket. However, they were also told that the rule is to place the ball in the blue basket. This procedure was repeated for 30 balls. The number of balls placed in the blue basket is informative about a subject's propensity to follow an arbitrary rule at the expense of personal payoffs.

Additionally, we asked subjects a series of questions in order to elicit their attitudes towards risk, intertemporal discounting, altruism, reciprocity and trust. These questions were English translations of the ones included in several waves of the German Socio Economic Panel (SOEP) survey $]^{8}$

\footnotetext{
${ }^{8}$ All questions are reproduced in full in Appendix A.4. The behavioral validity of the risk and intertemporal discounting questions was established with incentivized experiments (see Dohmen, Falk, Huffman, Sunde, Schupp, and Wagner, 2011. Vischer, Dohmen, Falk, Huffman, Schupp, Sunde, and Wagner, 2013).
} 
At the very end of the experiment, subjects were asked about their age, gender, and academic major. At that point they were also asked to provide their reasoning when making the contribution decision for "PGG No Rule" and, in the "endogenous institution" treatment, their reasoning when making the voting decision for the $M C R$.

\subsection{General procedures}

Before subjects entered the lab, they randomly drew a place card that specified at which computer terminal to sit. Subjects found paper copies of the consent form and the instructions for Part I at their assigned computer terminals. Subjects were informed that the experiment consists of several parts, but were not informed about the content of each part. At the beginning of each part, the instructions of that part were read out aloud to ensure common information regarding the content. The instructions to Part I and Part II included comprehension questions that had to be answered correctly before the respective part could begin. The instructions for Part I and the "endogenous institution" treatment of Part II can be found in Appendix A.4, together with screen shots of the decision-relevant stages. All sessions were conducted in English.

We conducted six sessions on three consecutive days in November 2014 in Maastricht, Netherlands, with 136 subjects in total and six sessions on three consecutive days in February 2015 in Zurich, Switzerland, with 136 subjects in total. Treatments were randomized across sessions and each treatment was run four times, twice in the morning and twice in the afternoon, twice in Maastricht and twice in Zurich. Each subject participated only once. Overall, 92 subjects participated in the "no institution" treatment, 88 subjects in the "exogenous institution" treatment, and 92 subjects in the "endogenous institution" treatment.

The sessions in Zurich took place at the Laboratory for Behavioral and Experimental Economics of the Department of Economics at the University of Zurich and the sessions in Maastricht took place at the Behavioral and Experimental Economics Laboratory (BEElab) of the School of Business and Economics at Maastricht University. The experiments were run with the software "z-Tree" (Fischbacher, 2007). We used the softwares "hroot" (Bock, Baetge, and Nicklisch, 2014) and "ORSEE" (Greiner, 2015) for recruitment. Subjects were students from the University of Zurich, the Swiss Federal Institute of Technology in Zurich and Maastricht University.

Sessions lasted about 2.5 hours. Payoffs from the experiment, denominated in "ECU," were converted into money at the rate of $65 \mathrm{ECU}$ to $€ 1$ (about $\$ 1.25$ at the time of the experiment) in Maastricht and 100 ECU to CHF 3 (about $\$ 3.25$ at the time of the experiment) in Zurich. Subjects were paid anonymously at the end of the experiment. On average, subjects earned $€ 22.52$ in Maastricht, with no show-up fee, and CHF 55.45 in Zurich, which included a show-up fee of CHF 10. The total payoff from the experiment equaled the sum of the payoffs in the five parts (plus the payment of a show-up fee in Zurich). For Parts I, III, IV, and V, subjects learned about the outcomes and their payoffs only at the very end of the experiment, after all decisions were made. 


\section{Results}

In presenting the results, we first explore contribution behavior in Part II, the part of the experiment during which the repeated two public good games were played and the treatments were introduced. We then jointly analyze Parts III and IV, to explore if and how the institutions introduced in Part II affect cooperative preferences and beliefs.

Before proceeding, we make a note on behavior, beliefs and preferences measured in the one-shot game in Part I in the different treatments. Figure 1(a) shows the average unconditional contributions and average beliefs about others' contributions and Figure 1(b) the average conditional cooperation preferences, in the one-shot public good game. There are almost no differences between treatments for all three measures and statistial tests confirm that these are not significant.9.$^{9}$ This lack of any difference is expected, as our treatment differences were not introduced until Part II, and shows that randomization across treatments was successful.

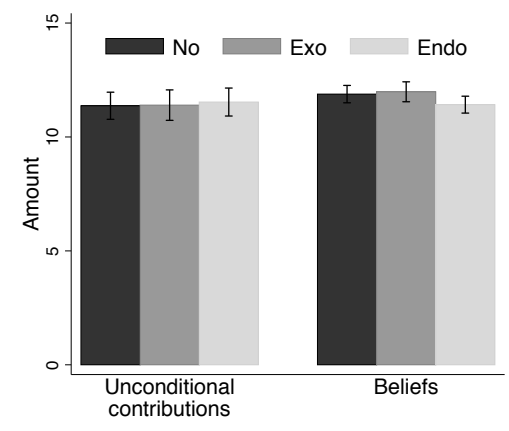

(a) Contributions and beliefs

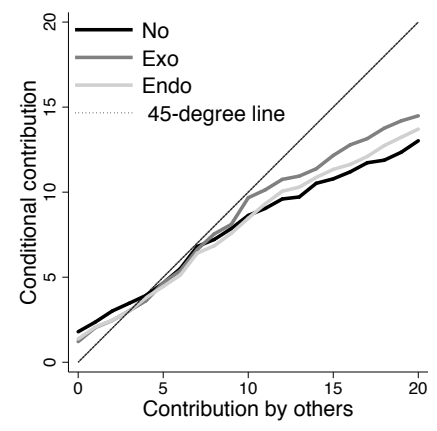

(b) Contribution preferences

Figure 1: Unconditional contributions, beliefs about others' contributions and cooperation preferences in Part I.

\subsection{Part II contributions}

In what follows we first report results pertaining to contributions in the two simultaneously played repeated public good games. Thereafter, we present the results regarding direct and spillover effects in the two treatments with institutions.

Figure 2 gives an overview of behavior in the three treatments during Part II. For each treatment, the figure shows the average contributions to "PGG No Rule" and to "PGG Rule", and - in treatments with institutions - the average $M C R{ }^{10}$

For the "no institution" treatment, Figure 2(a) shows that contributions to "PGG No Rule" and "PGG Rule" closely track each other and follow the typical declining pattern

\footnotetext{
${ }^{9}$ These results are from pair-wise treatment comparisons of unconditional contributions (Wilcoxon rank sum tests, $p \geq 0.750$ ) and pair-wise treatment comparisons of beliefs about others' contributions (Wilcoxon rank sum tests, $p \geq 0.346$ ). For comparing conditional cooperation preferences we construct an aggregate cooperation preference variable by taking the amount a subject decided to contribute, averaged across all possible contributions by others. Pair-wise treatment comparisons of this variable are also insignificant (Wilcoxon rank-sum tests, $p \geq 0.401$ ).

${ }^{10}$ In the "no institution" treatment, "PGG No Rule" refers to "Task Left" (i.e., the game on the left side of the subject's decision screen) and "PGG Rule" to "Task Right" (i.e., the game on the right side of the subject's decision screen).
} 
found in standard public good games. Average contributions to "PGG No Rule" ("PGG Rule") start at 11.45 (11.60) in the first period and decline steadily to 4.33 (5.23) in the last period. Averaged over all periods, there are no significant differences in contributions to "PGG No Rule" and "PGG Rule" (Wilcoxon signed-rank tests, $p=0.637$ ) 11 Thus, when no institution was present, on average subjects did not behave systematically differently in the two games. That there was little tendency to contribute differently between the two games is corroborated by group level data analysis (for details see Figure A.2(a) in Appendix A.2.2.

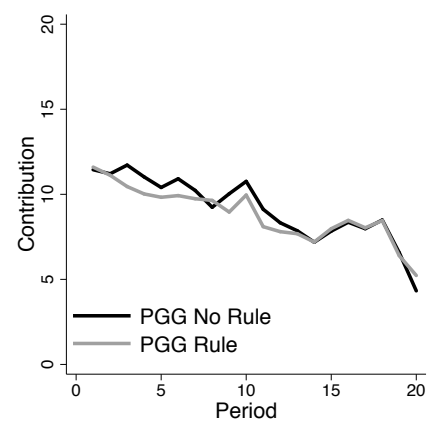

(a) No institution

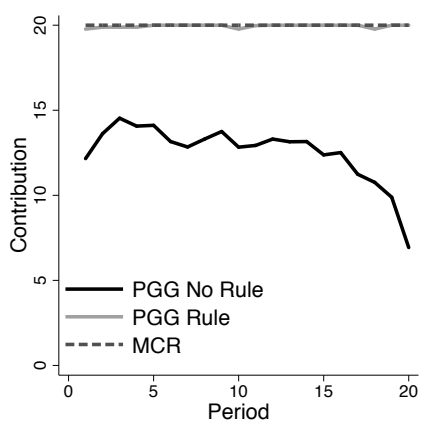

(b) Exogenous institution

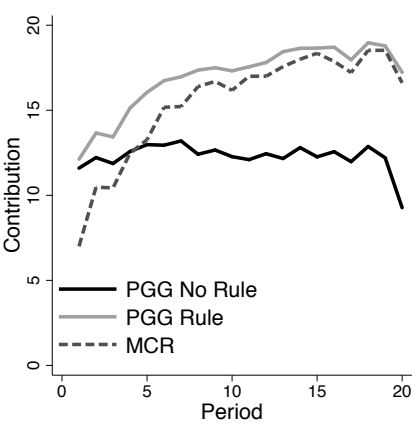

(c) Endogenous institution

Figure 2: Average contributions under "PGG No Rule" and "PGG Rule", and $M C R$

Turning to the "exogenous institution" treatment, Figure 2(b) shows that this institution is - as expected - highly effective in enforcing cooperative behavior in "PGG Rule". The $M C R$ of 20 was satisfied by 1753 of 1760 contribution decisions (99.6\%), yielding an average contribution to "PGG Rule" of 19.95 points. Average contributions to "PGG No Rule" start at 12.16 in the first period, slightly higher than in the "no institution" treatment, increase subsequently to reach a maximum of 14.53 in the third period, and thereafter decline steadily to 6.93 in the last period ${ }^{12}$

Figure 2(c) shows that, in the "endogenous institution" treatment, groups do not immediately implement very high $M C R$ 's in the "PGG Rule". The average implemented $M C R$ is 7 in the first period, but rises quickly and reaches an average of 17.75 in the final five periods. With the rise in the $M C R$, average contributions to "PGG Rule" increase over time. As in the "exogenous institution" treatment, the $M C R$ in "PGG Rule" was virtually never violated (it happened only in 2 out of 1840 observations). Average contributions to "PGG No Rule" start at 11.60 in the first period and remain between 11.60 and 13.20 until the 20th period, when the end-game effect kicks in and they decline to 9.27.

An interesting pattern in the "endogenous institution" treatment is that groups fail to implement very high $M C R$ 's, especially in the beginning, despite the fact that a $M C R$ of 20 makes full contributions a strictly dominant strategy for all group members. In the first period of Part II, subjects vote, on average, for a $M C R$ of 13.83 with the largest proportions voting for MCR's of 20 (28.26 percent), 15 (17.39 percent), and 10 (11.96

\footnotetext{
${ }^{11}$ If not indicated otherwise all statistical tests are two-sided and units of observation are the independent 4-person groups.

${ }^{12}$ At the group level, almost all groups contribute fully to "PGG Rule", whereas there is a fair amount of dispersion in average contributions to "PGG No Rule" (see Figure A.2(b) in Appendix A.2.2.
} 
percent) ${ }^{13}$ The votes for relatively low $M C R$ 's indicate that a sizable fraction of subjects need to learn that higher $M C R$ 's are beneficial. For instance, in period 1 the actual average payoff from "PGG Rule" was 32.12 ECU and only 4 out of 92 subjects earned more than 40 ECU, although a $M C R$ of 20 would guarantee a payoff of 40 ECU 14

Figure 3 provides a closer look at the individual voting decisions over the 20 periods and shows the fraction of votes for a $M C R$ of 20 , a $M C R$ between 10 and 19, and a $M C R$ below 10. The learning effect is clearly visible. While a minority of subjects initially vote for a $M C R$ of 20 , such votes quickly increase in frequency and reach levels of over 80 percent after period 10 . On the other hand, in every period, there are always at least 3 subjects (out of 92) who vote for thresholds below 10. Since the voting mechanism implements the minimal vote as the group's $M C R$, such subjects exert disproportionate influence. For example, in the first period, where 17.39 percent of votes for a $M C R$ of below 10 translate into 56.52 percent of groups with a $M C R$ of below 10 .

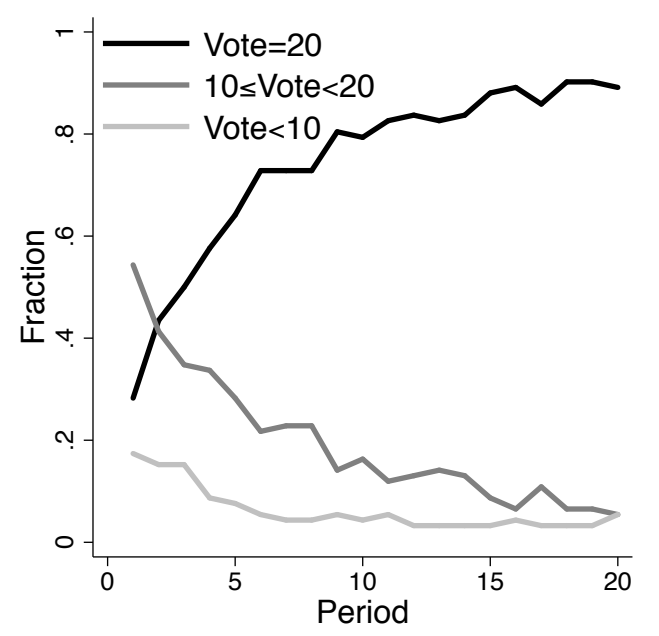

Figure 3: Voting behavior in the "endogenous institution" treatment.

\subsection{Direct and spillover effects of institutions}

In assessing the overall effectiveness of institutions, we distinguish between direct effects and spillover effects. Direct effects refer to the change in contributions brought about by the institution in the game where it applies ("PGG Rule"), relative to the contributions in the respective game in the "no institution" treatment, where there is never an institution.

\footnotetext{
${ }^{13}$ Subjects' votes in period 1 correlate significantly and positively with their beliefs about group members' contributions in Part I as well as their own unconditional contribution decision in Part I, but not with their average conditional contributions. Furthermore, female subjects tend to vote for lower $M C R$ 's. All other independent characteristics show no significant correlation (see Table A.6 in Appendix A.2.3.

${ }^{14}$ Dal Bó, Dal Bó, and Eyster (2017) suggest that subjects underestimate the equilibrium effects of institutions, which can lead to the demand for suboptimal policies. In our context, this could imply that subjects fail to realize that a low $M C R$ will generate incentives for others to provide low contributions. However, subjects' expected payoffs from "PGG Rule", given their contributions and their (non-incentivized) beliefs about the contributions of their group members, from Part I are even lower (31.14 ECU) than their actual payoff. This also holds for the pivotal voters in period 1, who had no reason to update their beliefs between their vote and their contribution decision. Hence, at least these pivotal voters knowingly voted for a $M C R$ that, given their stated beliefs, gave them a suboptimal payoff.
} 
Direct effects thus reflect the immediate influence of an institution. Spillover effects, in contrast, refer to the change in contributions brought about by the institution in the game where it does not apply ("PGG No Rule"), relative to the contributions in the respective game in the "no institution" treatment. Spillover effects thus reflect the derived or indirect effectiveness of an institution.

Direct effects. Comparing the contributions in "PGG Rule" across graphs in Figure 2 reveals that the exogenous and endogenous institutions clearly increase contributions in "PGG Rule" relative to the treatment without an institution. This direct effect is substantial and significant. Table 2 quantifies the direct effects across all periods as well as across periods 1-5, 6-10, 11-15, and 16-20. In the "exogenous institution" treatment, the direct effect amounts to 11.12 points (i.e., more than 50 percent of the endowment) over all periods and varies little over time (between 9.28 in the first five periods and 12.64 in the last five periods). In the "endogenous institution" treatment, the direct effect increases over time from 3.48 in the first five periods to 11.02 in the last five periods, which amounts to an overall effect of 8.12 . In both treatments, in all investigated blocks of periods the

Table 2: Direct and spillover effect of institutions on contributions in the "exogenous institution" treatment and the "endogenous institution" treatment

\begin{tabular}{ll|ccccc} 
& & \multicolumn{5}{|c}{ Period } \\
& & All & $1-5$ & $6-10$ & $11-15$ & $16-20$ \\
\hline \hline & Direct effect & 11.12 & 9.28 & 10.31 & 12.24 & 12.64 \\
& $($ s.e. $)$ & $(0.02)$ & $(0.07)$ & $(0.05)$ & $(0.00)$ & $(0.05)$ \\
& [p-value] & {$[0.000]$} & {$[0.000]$} & {$[0.000]$} & {$[0.000]$} & {$[0.000]$} \\
Exo & Spillover effect & 3.38 & 2.54 & 2.94 & 4.92 & 3.12 \\
& $(0.95)$ & $(0.83)$ & $(1.17)$ & $(1.28)$ & $(1.12)$ \\
& (s.e.) & {$[0.026]$} & {$[0.047]$} & {$[0.073]$} & {$[0.013]$} & {$[0.052]$} \\
& Relatulue] & 0.30 & 0.27 & 0.29 & 0.40 & 0.25 \\
& spillover effect & & & & & \\
& Direct effect & 8.12 & 3.48 & 7.53 & 10.47 & 11.02 \\
& (s.e.) & $(0.61)$ & $(0.79)$ & $(0.83)$ & $(0.66)$ & $(0.64)$ \\
& [p-value] & {$[0.000]$} & {$[0.001]$} & {$[0.000]$} & {$[0.000]$} & {$[0.000]$} \\
Endo & Spillover effect & 3.12 & 1.09 & 2.46 & 4.29 & 4.63 \\
$(\mathrm{~N}=23)$ & (s.e.) & $(1.02)$ & $(0.84)$ & $(1.13)$ & $(1.32)$ & $(1.31)$ \\
& [p-value] & {$[0.047]$} & {$[0.386]$} & {$[0.153]$} & {$[0.020]$} & {$[0.013]$} \\
& Relative size of & 0.38 & 0.31 & 0.33 & 0.41 & 0.42 \\
& spillover effect & & & & & \\
\hline
\end{tabular}

Notes: For each group in the treatments, the direct (spillover) effect equals the difference between that group's average contributions to "PGG Rule" ("PGG No Rule") and the average contributions of all groups to "PGG Rule" ("PGG No Rule") in the "no institution" treatment. $p$-values are from Wilcoxon rank-sum tests comparing the group-level contributions in "PGG Rule" ("PGG No Rule") of the "exogenous institution" treatment and the "endogenous institution" treatment, respectively, to contributions in "PGG Rule" ("PGG No Rule") in the "no institution" treatment. Relative size of spillover effect is the quotient of spillover and direct effect. 
increase relative to the "no institution" treatment is statistically significant (Wilcoxon ranksum test, $p \leq 0.001) .15$

Result 1. In both the "exogenous institution" treatment and the "endogenous institution" treatment, there are significantly positive direct effects of the institution. In both treatments, contributions are significantly higher under the presence of an institution than in the "no institution" treatment where an institution is never present.

Spillover effects. After having established that there are significant direct effects of institutions, the next question is if these direct effects spill over to the domain where there is no institution in place. Figure 4 visualizes for both treatments the spillover effects over time and Table 2 reports them for all periods and for blocks of five periods. Over all periods, spillover effects are significantly larger than zero in both the "exogenous institution" treatment and "endogenous institution" treatment (3.38 and 3.12, respectively; Wilcoxon rank-sum tests, $p=0.026$ and $p=0.047$, respectively). There is no significant difference between the "exogenous institution" treatment and the "endogenous institution" treatment (Wilcoxon rank-sum test, $p=0.856$ ). (We discuss the apparently different dynamics below.)

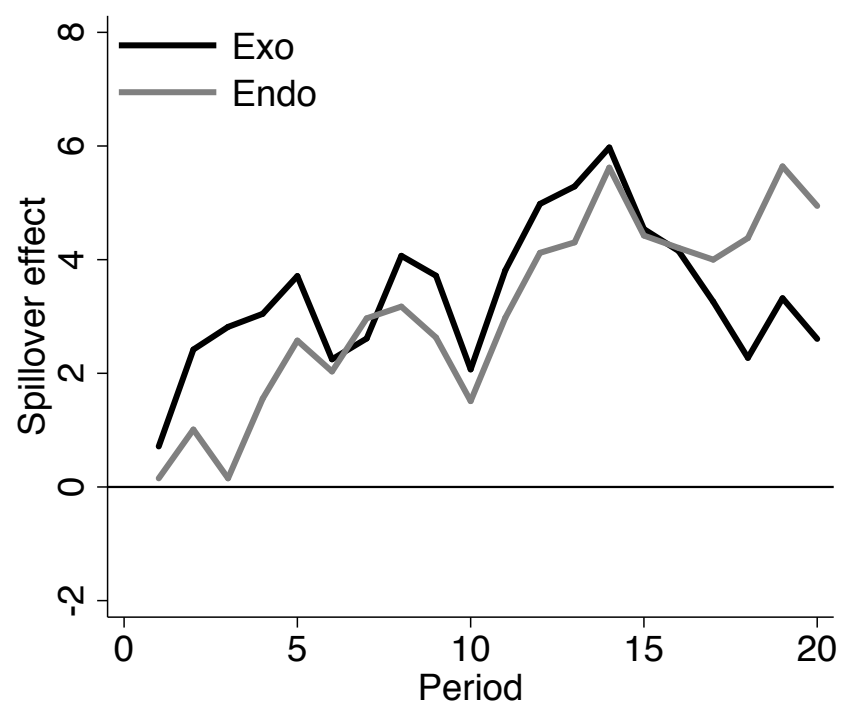

Figure 4: Spillover effect in "PGG No Rule".

The observed spillover effects are not only statistically significant but are also large in magnitude. Table 2 reports the relative size of the spillover effects defined as the spillover effect divided by the direct effect. Taken over all periods the relative spillover effect amounts to 0.30 and 0.38 in the "exogenous institution" treatment and the "endogenous institution" treatment, respectively. Thus, an institution that directly increases

\footnotetext{
${ }^{15}$ In all statistical tests regarding direct and spillover effects we compare the group averages in Task Left ("PGG No Rule") and Task Right ("PGG Rule") in the "no institution" treatment with those in the respective tasks in the "exogenous institution" treatment and "endogenous institution" treatment, respectively.
} 
contributions by 100 percent, in addition increases contributions by at least 30 percent in the domain beyond its direct control.

Result 2. In both the "exogenous institution" treatment and the "endogenous institution" treatment, the presence of an institution that directly increases contributions in one domain induces a significantly positive spillover effect and, therefore, leads to significantly increased contributions in the domain beyond the reach of the institution. In both treatments, the size of the spillover effect is economically substantial.

Welfare. Both effects contribute to increased overall welfare. Relative to the "no institution" treatment, the significant overall welfare gain in the "exogenous institution" treatment amounts to 14.51 additional points, of which 11.13 are due to the direct effect and 3.38 are due to the spillover effect (Wilcoxon rank-sum test, $p<0.001$ ). Similarly, relative to the "no institution" treatment, the significant overall welfare gain in the "endogenous institution" treatment amounts to 11.30 additional points, of which 8.18 are due to the direct effect and 3.12 are due to the spillover effect (Wilcoxon rank-sum test, $p<0.001)$.

Result 3. In both treatments, institutions that regulate cooperation in one domain significantly increase welfare both directly in the regulated domain and indirectly in the domain beyond their immediate effect.

Dynamics of spillover effects. We have seen that, taken over all periods, the average spillover effects do not differ between the "exogenous institution" treatment and the "endogenous institution" treatment. However, Figure 4 provides some indication that the dynamics of the spillover effects differ across treatments. Specifically, the spillover induced by the "endogenous institution" treatment is relatively small in the beginning, but strongly increases over time, whereas the spillover induced by the "exogenous institution" treatment does not show a clear trend. Consequently, in comparison to the "endogenous institution" treatment, the spillover effect is stronger in the "exogenous institution" treatment in the earlier periods, but weaker towards the end of the 20 periods.

These different dynamics in spillovers are statistically significant. According to Spearman rank order correlations the spillover effect in the "exogenous institution" treatment does not change significantly over time $(\rho=0.344, p=0.137)$, whereas the spillover effect in the "endogenous institution" treatment exhibits a significantly positive trend $(\rho=0.901, p<0.001)$. The separate statistics for blocks of five periods reported in Table 2 draw a similar picture. In the "exogenous institution" treatment the spillover effect is (marginally) significantly positive in all four blocks (Wilcoxon rank-sum tests, $p \leq 0.073$ ) and does not change much from periods 1-5 (2.54) to periods 16-20 (3.12). In contrast, in the "endogenous institution" treatment the spillover effect increases from 1.09 in periods $1-5$ to 4.63 in periods $16-20$. Moreover, the spillover effect is not statistically significantly different from zero in the first half of the 20 periods (Wilcoxon rank-sum tests, $p \geq 0.153$ ), but becomes highly significant in the second half (Wilcoxon rank-sum tests, $p \leq 0.020$ ) ${ }^{16}$

\footnotetext{
${ }^{16}$ The reported significance and dynamics of direct and spillover effects is corroborated by regression ananlysis (see Table A.1 in Appendix A.2.1)
} 
Result 4. The dynamics of spillover effects differ between treatments. The spillover effect from the endogenously adopted institution increases over time, whereas the spillover effect from the exogenously imposed institutions does not show a trend.

It seems reasonable that the different spillover dynamics in the "exogenous institution" treatment and the "endogenous institution" treatment are related to the differences in the development of the $M C R$. In the "exogenous institution" treatment, the $M C R$ is fixed at 20 throughout the experiment, whereas in the "endogenous institution" treatment it increases monotonically from a rather low level in the early periods to close to 20 in the later periods. Indeed, taking group averages over all periods, contributions to "PGG No Rule" and the MCR in "PGG Rule" are highly correlated (Spearman's rank order correlation, $\rho=0.315, p=0.009){ }^{17}$ This suggests that there is a positive relationship between the strength of the institution and the spillover effect it creates 18

Decomposing the spillover effects. An important remaining question is whether the spillover effects in the treatments with an institution stem primarily from free-riders who do not contribute in the "no institution" treatment starting to contribute positive amounts, or because subjects who already contribute in the "no institution" treatment contribute more, or both. We next explore this by studying the spillover effects on the extensive and intensive margins of contribuitons.

For each treatment, Figure 5(a) reports the fraction of subjects who contribute a positive amount in "PGG No Rule". It shows that there are little differences across treatments. Averaged over all periods, the frequency of positive contributions is 76.25 percent in the "no institution" treatment, 78.18 percent in the "exogenous institution" treatment, and 85.76 percent in the "endogenous institution" treatment. The differences are insignificant between the former two (Wilcoxon ranksum test, $p=0.991$ ), while in the "endogenous institution" treatment the fraction is marginally significantly higher (Wilcoxon ranksum tests, $p=0.098$ and $p=0.108$, respectively). The frequencies of positive contributions

\footnotetext{
${ }^{17}$ This result is confirmed in regression analysis (see Table A.4 in Appendix A.2.2 that disaggregates the period-level data within a group. However, the regression results have to be interpreted with caution as, in the "endogenous institution" treatment, behavior in past periods might both influence the implemented $M C R$ and contributions to "PGG No Rule".

${ }^{18}$ While it is not possible to completely rule out that selection plays a role in such a relationship, we have evidence that this is not the case. We test for selection effects by looking at two extreme cases of $M C R$ 's for which we have observations of randomly selected groups and groups that implemented the respective $M C R$ endogenously. First, in the "endogenous institution" treatment we only consider groups that implemented a $M C R$ of zero and compare their contributions to groups in the "no institution" treatment, in which there is also an implicit $M C R$ of zero. (We obtain the data for the "endogenous institution" treatment by averaging a group's contribution to "PGG No Rule" over all periods in which that group implemented a $M C R$ of zero. In total, six groups implemented a $M C R$ of zero at least once.) We find that contributions in the former and latter case are not significantly different (average contributions to "PGG No Rule": 7.64 and 9.15, respectively; Wilcoxon ranksum test, $p=0.572$ ). Second, we look at the 19 groups in the "endogenous institution" treatment that implemented a $M C R$ of 20 in some periods and compare their contributions to the "PGG No Rule" in those periods to the contributions to the "PGG No Rule" in the "exogenous institution" treatment. The average contributions in the former and the latter case are virtually identical (12.34 vs. 12.53; Wilcoxon ranksum test, $p=0.875$ ). Hence, at least in these two comparisons, groups that adopted a $M C R$ endogenously do not appear to behave differently than groups for which that $M C R$ was exogenously imposed. Another possibility could be that the $M C R$ influences contributions in "PGG No Rule" because subjects simply imitate their contributions to "PGG Rule" in "PGG No Rule". However, we don't find this to be the case. For a detailed analysis, see Appendix A.2.4
} 
exhibit decreasing trends and Spearman's rank order correlations show that the trend is similar in all treatments ("no institution" treatment: $\rho=-0.903$, "exogenous institution" treatment: $\rho=-0.927$, "endogenous institution" treatment: $\rho=-0.828 ; p<0.001$ ).

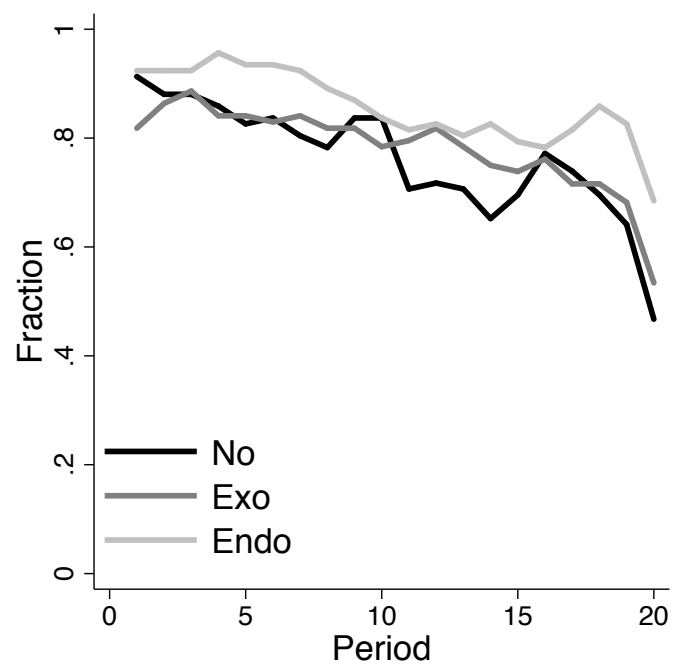

(a) Decision to contribute positive amount

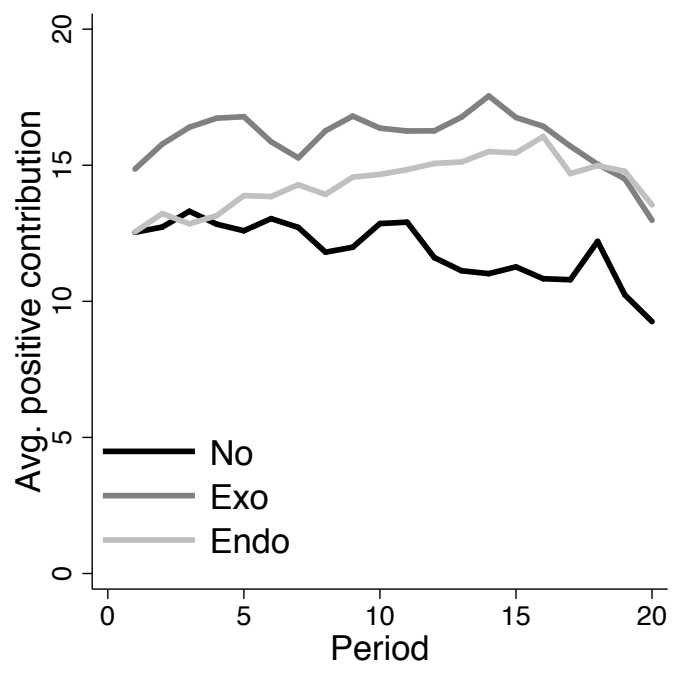

(b) Level of contribution conditional on positive contribution

Figure 5: Decision to contribute and level of contribution conditional on positive contribution.

The picture changes when looking at average contributions conditional on having contributed a positive amount, shown in Figure 5(b). Averaged over all periods, contributions are (marginally) significantly higher in the "exogenous institution" treatment (15.64) and the "endogenous institution" treatment (13.91) than in the "no institution" treatment (11.49) (Wilcoxon ranksum tests, $p=0.001$ and $p=0.073$, respectively). The difference between the "exogenous institution" treatment and the "endogenous institution" treatment is not significant (Wilcoxon ranksum test, $p=0.128$ ). There is a pronounced difference in the development of average conditional contributions over time. In the "no institution" treatment contributions decline (Spearman's $\rho=-0.770, p<0.001$ ), they appear to be stable in the "exogenous institution" treatment $(\rho=-0.179, p=0.450)$ and they are increasing in the "endogenous institution" treatment $(\rho=0.698, p=0.001)$.

A regression analysis corroborates these findings. Table 3 shows the two stages of a hurdle model. In Stage 1, a Probit regression estimates the effect of treatments, period, and treatment-period interactions on the decision to contribute. The results show that both treatments (variables "Exo" and "Endo") do not have a significant level effect on the decision to contribute something positive. The variable "Period" has a significantly negative effect, indicating that the likelihood to contribute a positive amount is decreasing over time in the "no institution" treatment. The trend is the same in the "exogenous institution" treatment and in the "endogenous institution" treatment, as shown by the insignificant interaction variables. 
Table 3: Decision to contribute and contributions to "PGG No Rule"

\begin{tabular}{|c|c|c|}
\hline & $\begin{array}{l}\text { Hurdle } \\
\text { Stage } 1\end{array}$ & $\begin{array}{l}\text { Hurdle } \\
\text { Stage } 2\end{array}$ \\
\hline No (constant) & $\begin{array}{c}1.294^{* * *} \\
(0.193)\end{array}$ & $\begin{array}{c}13.213^{* * *} \\
(0.921)\end{array}$ \\
\hline Exo & $\begin{array}{l}-0.087 \\
(0.285)\end{array}$ & $\begin{array}{c}3.142^{* * *} \\
(1.069)\end{array}$ \\
\hline Endo & $\begin{array}{c}0.298 \\
(0.290)\end{array}$ & $\begin{array}{l}-0.341 \\
(1.242)\end{array}$ \\
\hline Period & $\begin{array}{c}-0.052^{* * *} \\
(0.008)\end{array}$ & $\begin{array}{c}-0.161^{* *} \\
(0.068)\end{array}$ \\
\hline Exo $\times$ Period & $\begin{array}{c}0.013 \\
(0.015)\end{array}$ & $\begin{array}{c}0.122 \\
(0.086)\end{array}$ \\
\hline Endo $\times$ Period & $\begin{array}{c}0.006 \\
(0.012)\end{array}$ & $\begin{array}{c}0.289^{* * *} \\
(0.097)\end{array}$ \\
\hline Observations & 5440 & 4357 \\
\hline \multicolumn{3}{|c|}{$\begin{array}{l}\text { Notes: The baseline category "No (constant)" } \\
\text { is a binary variable that indicates the "no in- } \\
\text { stitution" treatment. The dependent variable } \\
\text { in regression (1) is a dummy that equals } 1 \text { if } \\
\text { contribution is positive and } 0 \text { otherwise. The } \\
\text { dependent variable in regression (2) is the level } \\
\text { of contributions to "PGG No Rule" conditional } \\
\text { on a positive contribution. Stage } 1 \text { is a Probit } \\
\text { regression; Stage } 2 \text { is a linear regression trun- } \\
\text { cated at } 0 \text {. Robust standard errors (clustered } \\
\text { on part-II groups) in parentheses. }{ }^{*} p<0.10 \text {, } \\
{ }^{* *} p<0.05,{ }^{* * *} p<0.01\end{array}$} \\
\hline
\end{tabular}

In Stage 2 the hurdle model estimates a linear regression model truncated at zero. That is, it measures the effect on the level of contribution, conditional on a positive contribution. The estimation results show that the "exogenous institution" treatment leads to significantly higher contribution levels compared to the "no institution" treatment, while there is no such effect for the "endogenous institution" treatment. Similar to the decision to contribute, the level of contributions is significantly decreasing over time in the "no institution" treatment. This negative trend is offset in the "exogenous institution" treatment. Although, the difference with the "no institution" treatment is not significant, it is the case that the trend in the "exogenous institution" treatment is statistically not different from zero $($ Period + Exo $\times$ Period $=0, p=0.453$, Wald test $)$. The negative trend in the "no institution" treatment is effectively overturned in the "endogenous institution" treatment and contribution levels rise significantly over time $($ Period + Endo $\times$ Period $=0$, $p=0.067$, Wald test).

Result 5. Decomposing the spillover effect shows that it is mainly due to an effect on the level of contributions conditional on contributing a positive amount. There is no significant effect on the decision to make a positive contribution. 
Thus, effective institutions in "PGG Rule" do not induce complete free riders to start contributing in "PGG No Rule". Rather, the spillover effect works on those who contribute something even without enforcement institutions, by leading them to contribute more.

\subsection{Persistent effects of institutions on behavior, beliefs and preferences}

We next analyze if the experience of an enforcement institution in "PGG Rule" has a persistent effect on cooperative behavior, beliefs about others' cooperativeness, and preferences for cooperation. For this purpose, we use data from Parts III and IV, in which we elicited these variables for each subject. Recall that in these parts subjects engaged in a one-shot strategy method public goods game without an enforcement institution and also provided beliefs about others' cooperativeness. In Part III subjects interacted in the same group as in Part II, whereas in Part IV they interacted with subjects they had previously not encountered.

We first explore if the effect of an enforcement institution on contribution behavior persists even after removal of the institution. Figure 6(a) shows that there are indeed clear differences in average unconditional contributions, across treatments in Parts III and IV 19 In particular, unconditional contribution levels in the "exogenous institution" treatment and the "endogenous institution" treatment are significantly higher than in the "no institution" treatment Part III (Wilcoxon rank-sum tests, $p=0.009$ and $p=$ 0.002). In Part IV unconditional contributions are insignificantly higher in the "exogenous institution" treatment (Wilcoxon rank-sum tests, $p=0.173$ ) and significantly higher in the "endogenous institution" treatment (Wilcoxon rank-sum tests, $p=0.017$ ) ${ }^{20}$

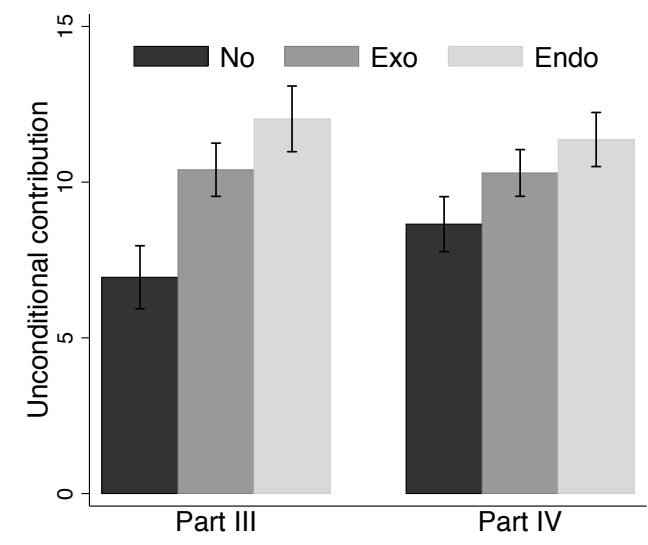

(a) Unconditional contribution

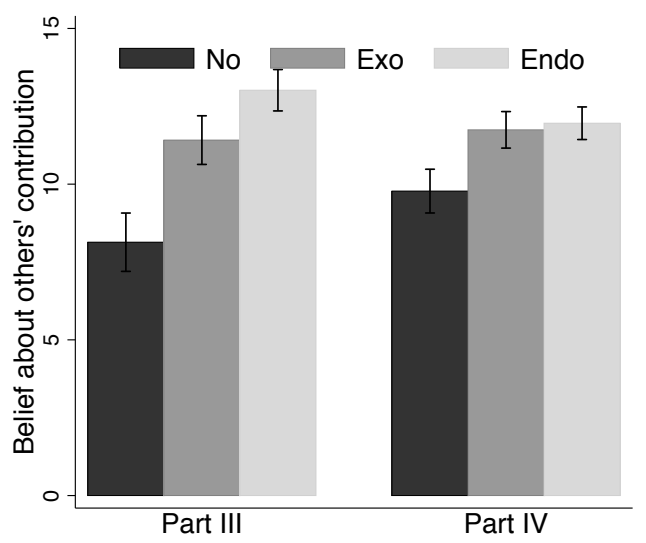

(b) Belief interval - midpoint

Figure 6: Treatment effects on own contributions and beliefs about others' contributions.

These treatment effects on unconditional contributions could be driven by an effect on beliefs about others' contributions, which we explore next. Figure 6(b) reveals that the

\footnotetext{
${ }^{19}$ The associated mean values, standard errors and econometric test results for contribution behavior as well as beliefs and cooperation preferences are summarized in Appendix A.3. Tables A.10 to A.12.

${ }^{20}$ In comparison to Part I contributions decrease in Parts III and IV in the "no institution" treatment (Wilcoxon signed-rank tests, $p \leq 0.002$ ), whereas this is not the case in the "exogenous institution" treatment and the "endogenous institution" treatment (Wilcoxon signed-rank tests, $p \geq 0.168$ ).
} 
average midpoints of belief intervals about others' contributions indeed follow a pattern similar to subjects' own unconditional contributions. Statistical tests corroborate this visual impression. Beliefs about others' cooperativeness are significantly higher in the "exogenous institution" treatment and the "endogenous institution" treatment than in the "no institution" treatment (Part III: $p=0.012$ and $p<0.001$; Part IV: $p=0.047$ and $p=0.014$; Wilcoxon rank-sum tests). There is no significant difference between the two treatments with an institution (Wilcoxon rank-sum tests, $p \geq 0.196$ ). Thus, in comparison to the "no institution" treatment, experience with either the endogenously created or the exogenously imposed institution has a strong positive effect on beliefs about the cooperativeness of others 21

Finally, we investigate the effect of experienced institutions on cooperation preferences. Figure $7(\mathrm{a})$ 7(b) show the average conditional contribution levels for each possible average contribution by the other group members in Part III and IV, respectively. Figure 7(c) shows an aggregate cooperation preference variable constructed by taking the amount a subject decided to contribute, averaged across all possible contributions by others. From all three figures it can be seen that preferences exhibit less cooperation in the "no institution" treatment than in the treatments where subjects experienced institutions in Part II.

We use the aggregate measure to test statistically for differences between treatments. The tests show that in Part III and Part IV, average cooperation preferences in the "exogenous institution" treatment and the "endogenous institution" treatment are significantly stronger than in the "no institution" treatment (Wilcoxon rank-sum tests, $p \leq 0.024$ ). Thus, the experience of institutions in Part II not only shape beliefs but also cooperation preferences toward others 22

Result 6. In comparison to the "no institution" treatment, the experience of an institution that enforces cooperation increases cooperative behavior, beliefs about others' cooperativeness as well as preferences for cooperation, even after the institution ceases to exist. This extends to behavior, beliefs and preferences toward strangers, with whom there was no prior interaction.

This result has two important implications. First, institutional spillovers are not limited to concurrent decisions, but can affect behavior in subsequent games and interactions with new groups of people. Second, institutions affect beliefs about others cooperativeness as well as own cooperation preferences, suggesting that both are likely mechanisms behind the spillover effects observed in Part II.

\footnotetext{
${ }^{21}$ In comparison to Part I, in the "no institution" treatment, the average midpoint of the provided belief intervals is significantly lower in Part III and Part IV (Wilcoxon signed-rank test, $p<0.001$ and $p=0.002$ ), while in the "exogenous institution" treatment beliefs do not change (Wilcoxon signed-rank test, $p \geq 0.291$ ). In the "endogenous institution" treatment beliefs do also not change from Part I to Part IV and even increase to Part III (Wilcoxon signed-rank tests, $p=0.260$ and $p=0.018$ ).

${ }^{22}$ In comparison to Part 1 , in the "no institution" treatment average cooperation preferences strongly decrease in Part III and IV (Wilcoxon sign-rank tests, $p<0.001$ ). In both treatments with enforcement institutions in Part II, cooperation preferences stay the same or decrease only weakly from Part I to Part III and IV, respectively ("exogenous institution" treatment: $p=0.064$ and $p=0.127$; "endogenous institution" treatment: $p=0.412$ and $p=0.094$; Wilcoxon sign-rank tests).
} 


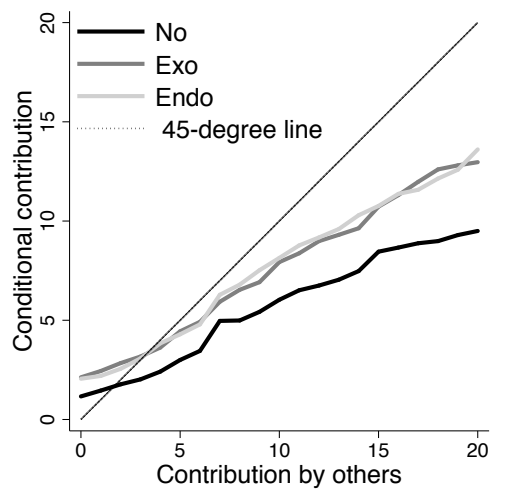

(a) Part III

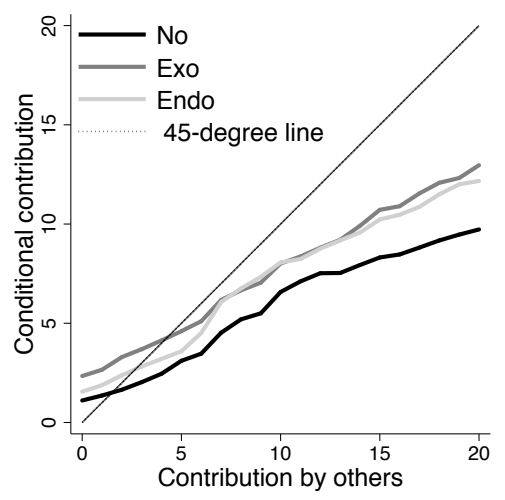

(b) Part IV

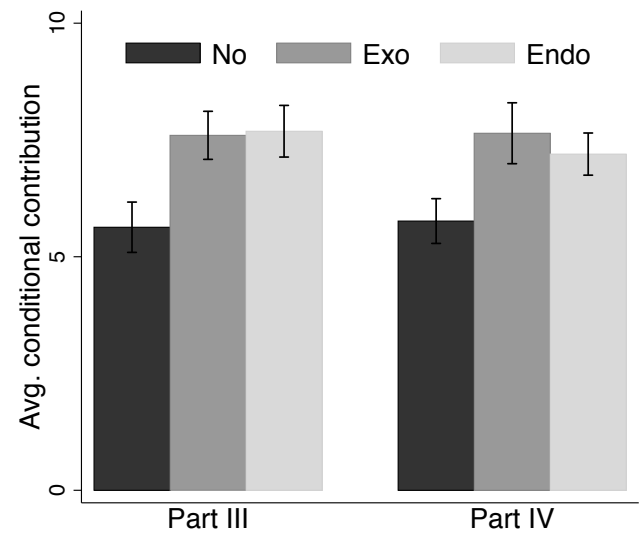

(c) Average cooperation preferences

Figure 7: Treatment effects on cooperation preferences.

\section{Spillover effects: The role of endogenous institutions and increasing strength of institutions}

The treatments studied thus far show that institutions induce positive spillover effects and that these spillovers differ between an exogenously implemented and an endogenously adopted institution. However, this difference could not cleanly be attributed to the difference in exogeneity versus endogeneity, because in the "endogenous institution" treatment the minimum contribution requirement, $M C R$, started at a relatively low level and increased over time, whereas in the "exogenous institution" treatment the $M C R$ was fixed at the maximum contribution throughout all periods. Therefore, it is an open question if the difference in spillovers between treatments is due to endogeneity or due to the different time path of the strength of the institutions.

To disentangle these two potential explanations, we conducted a follow-up study comprising two additional treatments. First, the "endogenous 0-20 institution" treatment facilitates the endogenous uptake of 20 as the implemented $M C R$ right from the beginning and thus yields a cleaner comparison to the "exogenous institution" treatment. Second, the "exogenous yoked institution" treatment implements the average $M C R$ observed in the "endogenous institution" treatment exogenously for a new set of subjects and thus yields a clean comparison to the latter treatment. These two additional treatments differ 
from the already reported ones only in the way the $M C R$ is implemented in Part II. All other parts are unchanged.

We conducted additional sessions in February 2016. Only subjects that had not participated in any of the earlier sessions were invited. As before, we ran four sessions per treatment, two at Maastricht University and two at the University of Zurich. In total, we collected data from 192 additional subjects, equally distributed between the "endogenous 0-20 institution" treatment and the "exogenous yoked institution" treatment.

\subsection{The "endogenous 0-20 institution" treatment}

Part II of the "endogenous 0-20 institution" treatment differs in two aspects from the original "endogenous institution" treatment. First, in each period, group members could only vote for a $M C R$ of either 0 or 20 . Second, the unanimity requirement was replaced by a simple majority rule; that is, a $M C R$ of 20 was implemented whenever three or more out of four group members voted for it, otherwise the $M C R$ was zero.

These changes were meant to facilitate the implementation of a $M C R$ of 20 and they were very effective in doing so, as the average implemented $M C R$ is 18.67 . Out of 480 periods, an $M C R$ of 20 is implemented in 448 periods, i.e., $93.33 \%$ of all periods. Moreover, 17 out of 24 groups implement a $M C R$ of 20 in all 20 periods and only one group adopted an $M C R$ of 0 in most periods (see Figure A.3 in Appendix A.2.2 for the distributions of implemented MCR's). There is also no discernible time trend in the evolution of the $M C R$; already in the first period the average implemented $M C R$ is 16.67 and it remains even higher thereafter (see Figure A.1(b) in Appendix A.2.2.

The average contribution to "PGG Rule" in the "endogenous 0-20 institution" treatment is 19.13, which is significantly greater than in the "no institution" treatment and not significantly different from the "exogenous institution" treatment (Wilcoxon ranksum tests, $p<0.001$ and $p=0.385$, respectively). Overall, the endogenously implemented $M C R$ in the "endogenous 0-20 institution" treatment has a strong direct effect and its effectiveness is comparable to the exogenously implemented $M C R$ of 20 in the "exogenous institution" treatment (see Figure A.1(a) and Figure A.1(b) in Appendix A.2.2. Hence, in terms of a direct effect, this treatment yields a highly effective endogenously determined institution.

Figure 8(a) shows the spillover effect in the "endogenous 0-20 institution" treatment, together with the spillover effect in the "exogenous institution" treatment. The figure suggests a positive but weak spillover effect in the "endogenous 0-20 institution" treatment. Indeed, across all periods, the average spillover effect amounts to 0.71 , but is not significantly different from zero (Wilcoxon ranksum test, $p=0.595$ ) and is significantly smaller than the effect in the "exogenous institution" treatment (Wilcoxon ranksum test, $p=0.036){ }^{23}$ There is also no statistically significant time trend (Spearman's $\rho=-0.353$, $p=0.126)$.

Result 7. The consistently strong endogenous institution in the "endogenous 0-20 institution" treatment induces a positive but insignificant spillover effect, which remains constant over time.

\footnotetext{
${ }^{23}$ See Table $\mathrm{A} .2$ in Appendix $\overline{\text { A.2.2 }}$ for an overview of non-parametric tests.
} 
Given the significant spillover effect in the "exogenous institution" treatment, the virtual absence of it in the "endogenous 0-20 institution" treatment appears puzzling. A possible explanation could be that the instances in which a $M C R$ of 0 was implemented resulted in very low contribution levels. It indeed holds that the average contributions to "PGG No Rule" are lower when a $M C R$ of 0 instead of a $M C R$ of 20 is implemented (7.65 vs 10.02). However, considering only those groups and periods in which a $M C R$ of 20 is implemented does not lead to a significant difference compared to the "no institution" treatment. Alternatively, it could be that the deviation from unanimity in implementing the $M C R$ weakens the spillover effect. To explore this possibility we analyze whether groups in which only three subjects voted for a $M C R$ of 20 behave differently from those in which four subjects did so. We do not find a significant difference between these two cases.

It is also not the case that, conditional on voting for 20 , subjects contributed different amounts depending on whether two or three other group members also voted for 20 (for an overview of these results, see Table A.7 in Appendix A.2.2. Hence, while we cannot completely rule out that weakening the unanimity requirement had some negative effect on contributions in "PGG No Rule", we cannot detect any such effect in our data. It remains an open question why the "endogenous 0-20 institution" treatment exhibits a weaker spillover effect than "exogenous institution" treatment, despite the institutions having similarly strong direct effects. However, it is clear that the endogeneity of an institution alone is not sufficient to produce strong positive spillovers ${ }^{24}$

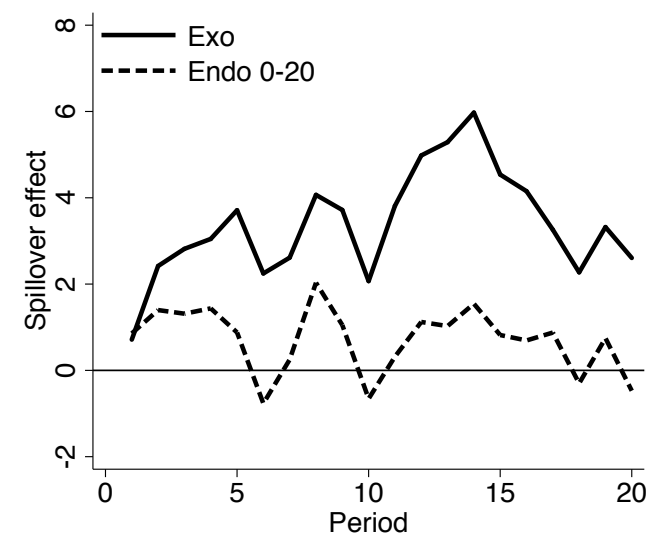

(a) Strong and stable institution

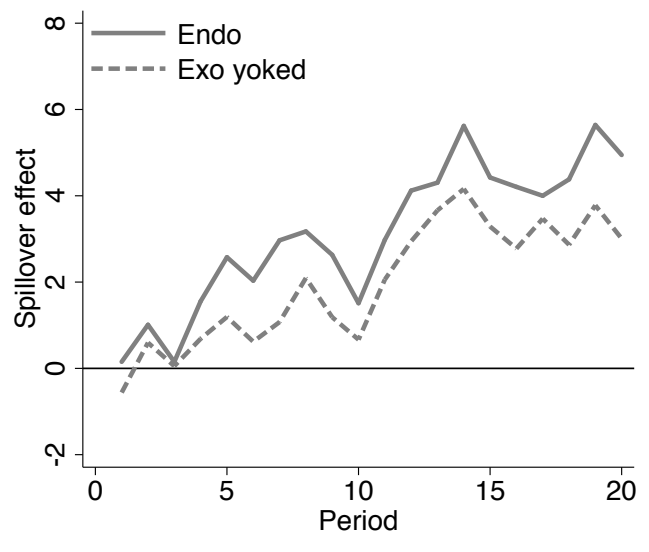

(b) Institution strengthens over time

Figure 8: Spillover effects to "PGG No Rule".

\footnotetext{
${ }^{24}$ In Part I there are no significant differences between the "endogenous 0-20 institution" treatment and the "no institution" treatment, regarding unconditional contributions, beliefs about others' contributions and average cooperation preferences (Wilcoxon ranksum tests, $p \geq 0.725$ ). Since there is no strong spillover effect in the "endogenous 0-20 institution" treatment it is not surprising that we also do not find strong differences in unconditional contributions, beliefs and average cooperation preferences between the "endogenous 0-20 institution" treatment and the "no institution" treatment in Part III and IV, respectively (Wilcoxon ranksum tests, $p \geq 0.198$ ). For all non-parametric tests, see Table A.10 A.12 in Appendix A.3)
} 


\subsection{The "exogenous yoked institution" treatment}

In Part II of the "exogenous yoked institution" treatment, we exogenously implemented an $M C R$ in each period equal to the average of the $M C R$ endogenously adopted in the "endogenous institution" treatment in the same period, rounded to the nearest integer. Thus, subjects in the new treatment faced, on average, the same upward trending $M C R$ as subjects in the "endogenous institution" treatment.

The direct effect in the "exogenous yoked institution" treatment is comparable to the one in the "endogenous institution" treatment. Contributions to "PGG Rule" in the new treatment increase in a similar way as they do in the "endogenous institution" treatment (see Figure A.1(c) and Figure A.1(d) in Appendix A.2.2). Averaged over all periods, there are no significant differences between the two treatments with respect to contributions to "PGG Rule" (16.95 in the "endogenous institution" treatment vs 17.38 in the "exogenous yoked institution" treatment; Wilcoxon ranksum test, $p=0.511$ ). The same holds for the spillover effect, which is shown in Figure 8(b), together with the spillover effect in the "endogenous institution" treatment. Over all periods, the average spillover effect is somewhat weaker in the "exogenous yoked institution" treatment (1.98) than in the "endogenous institution" treatment (3.12), but the difference is statistically insignificant (Wilcoxon rank-sum test, $p=0.444$ ). As in the "endogenous institution" treatment, the spillover effect in the "exogenous yoked institution" treatment exhibits a significantly increasing trend (Spearman's $\rho=0.854, p<0.001$ ). These results are corroborated by regression analyses (see Table A.3 in Appendix A.2.

Result 8. Institutions that are initially weak, but strengthen over time lead to an increasing spillover effect. The effect is independent of whether the institutions are endogenously adopted or exogenously imposed.

Finally, consistent with our findings for the "endogenous institution" treatment, the increasing spillover effect in the "exogenous yoked institution" treatment appears to be due to an increase of contributions among those subjects who already contributed some positive amount and not to a change in the decision whether to contribute at all (see Table A.5 in Appendix A.2.2 25

\section{Discussion}

Our results clearly demonstrate the existence of spillover effects from an environment governed by an institution ("PGG Rule") to behavior in an environment not governed by an

\footnotetext{
${ }^{25}$ Concerning Parts I, III and IV, the results in the "exogenous yoked institution" treatment are consistent with those in the "endogenous institution" treatment, but the effects are slightly weaker. In Part I, compared to the "no institution" treatment, there are no significant differences with respect to unconditional contributions, beliefs about others' contributions and cooperation preferences (Wilcoxon ranksum tests, $p \geq 0.693$ ). In Part III, the "exogenous yoked institution" treatment leads to significantly higher unconditional contributions and beliefs about others' contributions compared to the "no institution" treatment (Wilcoxon ranksum test, $p=0.012$ and $p=0.029$ ). There is also an increase in cooperation preferences but it fails to reach statistic significance (Wilcoxon ranksum test, $p=0.302$ ). In Part IV, with respect to strangers, unconditional contributions, beliefs about others' contributions and cooperation preferences are higher than in "no institution" treatment, but the differences are not quite statistically significant (Wilcoxon ranksum tests, $p \geq 0.108$ ). For details, see Tables A.10 A.12.
} 
institution ("PGG No Rule"). We find evidence of such spillovers both when institutions are exogenously imposed (in the "exogenous institution" treatment and the "exogenous yoked institution" treatment) and when they are endogenously determined (in the "endogenous institution" treatment, but not in the "endogenous 0-20 institution" treatment). Moreover, our results show that the experience of an institution affects both beliefs and cooperation preferences in subsequent interactions with the same group members and with strangers.

While our goal is not to identify a single mechanism as the main driver of spillovers, the latter results strongly suggest that the observed spillover effects are due both to an influence of institutions on beliefs regarding others' cooperativeness and an effect on cooperative preferences. However, other channels through which the spillover effects may have occurred are conceivable. Here, we consider some of the possibilities.

The fact that the spillover effects are positive rules out mechanisms that predict negative effects, such as crowding out and pure altruism. Such mechanisms are inconsistent with the observation of increased contributions in "PGG No Rule" as a result of increased enforced contributions in "PGG Rule".

One remaining potential channel is that subjects generalize simple rules that are provided to them and apply them broadly. In our experiment the institution in "PGG Rule" provides such a rule, corresponding to high contributions. In Part V we elicited rulefollowing propensity (RFT), which provides a means of testing whether subjects who are more willing to follow an arbitrary rule in the RFT are also more willing to follow the social rule highlighted by the institution in "PGG Rule" (cf. Kimbrough and Vostroknutov (2016b)). However, we find no significant effects of the interactions between subjects' rule-following propensity and any of the treatments with an institution (see column (1) of Table A.9 in Appendix A.2.5. This suggests that rule following is not an important reason for the observed spillover effects.

Another related potential preference channel is provided by the Social Heuristics Hypotheses $(\mathrm{SHH})$, which proposes that cooperative norms establish simple heuristics that are followed intuitively. We can explore whether this channel is active using the results from the Cognitive Reflection Test (CRT), which we elicited in Part V. CRT scores are inversely related to a tendency to rely on intuition in answering questions with an immediate intuitive, but incorrect, answer. According to SHH, if the institution in "PGG Rule" provides a heuristic for cooperation, then subjects who score lower on cognitive reflection should follow the norm intuitively and contribute more in other choices (cf. the argument in Peysakhovich and Rand (2016)). We find a negative significant effect of the interaction between the CRT score and the treatments with institutions only for the "exogenous institution" treatment (see column (2) of Table A.9 in Appendix A.2.5. Thus, there is only weak - at best suggestive - evidence consistent with the idea that heuristic thinkers exhibit greater positive spillover effects.

Finally, in Parts III and IV we saw that institutions positively affect beliefs, compared to the case without an institution. Hence, beliefs are a potentially important channel for spillover effects. However, beliefs in Parts III and IV do not only reflect a pure insti- 
tution effect because they are influenced by the history of experienced contributions in Part II, which in turn are potentially influenced by the existence of an institution. The (non-incentivized) beliefs in period 1 of Part II can provide additional information on the potential role of beliefs without this additional effect. Beliefs in period 1 were elicited before any contribution decision was made or observed, but after the institution was implemented. An analysis of these beliefs shows that in the "exogenous institution" treatment and in the "endogenous 0-20 institution" treatment, in period 1, beliefs about others' cooperativeness are at least marginally significantly higher than in the "no institution" treatment (12.43 and 12.56 vs 11.34; Wilcoxon rank-sum tests, $p=0.054$ and $p=0.044$ ). There are no significant differences in beliefs for the "endogenous institution" treatment or the "exogenous yoked institution" treatment and the "no institution" treatment, likely because the $M C R$ was not high enough in period 1. Interestingly, in the "endogenous institution" treatment there is a positively significant correlation between the implemented $M C R$ and beliefs (Spearman's $\rho=0.279, p=0.007$ ) ${ }^{26}$ Hence, the evidence from beliefs in period 1 further supports the idea that institutions in "PGG Rule" affect beliefs in "PGG No Rule", which in turn increases contributions in "PGG No Rule", thus creating at least part of the spillover effects.

\section{Conclusion}

In this paper we test whether an institution that has a powerful direct effect on behavior in one domain also influences how cooperatively a group acts in another domain where the institution exerts no direct influence. We find clear evidence in favor of such spillover effects, though their magnitude appears to vary depending on the nature of the institution. While some of our treatments suggest that there may be differences in spillover effects between exogenously imposed and endogenously adopted institutions, with the former having stronger spillover effects that increase over time. However, additional treatments indicate that the increasing spillover effect in the endogenous institution is due to the increasing strength of the institution and that the endogenous establishment of the institution does not have a significant additional effect on spillovers.

We also find that both types of institutions have effects that persist beyond their presence. Treated subjects have more positive beliefs about others' contributions and they contribute more, both conditionally and unconditionally. These effects also extend to new counterparts, with whom no previous interaction occurred. This, together with evidence that beliefs are positively affected by the mere presence of an institution, strongly

\footnotetext{
${ }^{26}$ In the "exogenous yoked institution" treatment, there is no variation in the $M C R$ and thus no such relationship possible. The above tests use individual observations because, in period 1, subjects did not yet receive feedback about contributions by their group members and thus individual observations of beliefs about these contributions can be treated as independent. However, in the "endogenous institution" treatment and the "endogenous 0-20 institution" treatment subjects received feedback about the group voting outcome before stating their beliefs in period 1. Applying the conservative approach of using groups as independent observations in period 1, the difference between the "no institution" treatment and the "endogenous 0-20 institution" treatment and correlations between the $M C R$ and beliefs in the "endogenous institution" treatment are significant with parametric regressions clustered on the group level $(p=0.098$ and $p=0.050$, respectively) but fail to reach significance with non-parametric tests using group averages (Wilcoxon rank-sum test, $p=0.135$; Spearman's $\rho=0.325, p=0.130$ ).
} 
suggests that spillover effects are due to combined changes in preferences for cooperation and changes in beliefs about others' contributions.

Understanding spillover effects is important for evaluating the overall effectiveness of institutions. As our results show, the extent to which an institution improves welfare and efficiency is only partly determined by changes in the behaviors it directly governs. Large indirect effects may also obtain through how an institution influences behavior in other domains. In our case, such effects are positive, making the institution more effective than one would surmise merely by looking at how it affects the regulated behavior. Moreover, we also show that such effects may be long-lived and last into future novel interactions. Our results thus suggest that policymakers should account for such potential spillover effects in evaluating the impacts of policies.

From a broader perspective, our study can also speak to the literature on the interrelation between institutions and culture (Guiso, Sapienza, and Zingales, 2006, 2008; Tabellini, 2008, 2010, Alesina and Giuliano, 2015, Gächter and Schulz, 2016). The set of beliefs and preferences that the members of a society hold are commonly acknowledged as important determinants of a society's culture. In this regard, we provide causal evidence that institutions can shape culture persistently, and that the institutionally induced change in culture can lead to sizable welfare effects.

Needless to say that more work is necessary to understand when and how the behavioral effects of institutions extend to unregulated behaviors and settings. One interesting open question concerns the dynamics of cooperative behavior in the long run. In reality, it is often infeasible to increase the strength of institutions indefinitely. Therefore, it could be that the positive spillover effects on voluntary cooperation start to decrease once such an upper bound is reached. Similarly, in the long run, cooperative behavior without institutions has been shown to break down completely. It would be interesting to study whether this also holds for spillover effects induced by our strong and stable institutions, or whether cooperation eventually stabilizes at some positive level.

Our study is only an initial step in investigating how institutions that incentivize pro-social behaviors in some domains spill over to influence pro-social behaviors in other domains. Many other institutions and settings are conceivable, and we only explore a very small part of this set. For example, while our exogenously implemented institution costlessly enforced the socially most efficient cooperation level, many institutions in the field are not fully efficient or come at some other costs. This may limit or negate the positive spillovers from an institution. Future research should, therefore, examine spillover effects more broadly, across a wide variety of contexts and institutional features. Our study provides an experimental set-up that can be used as an easily extendable workhorse for this purpose. 


\section{References}

Alesina, A., And P. Givliano (2015): "Culture and Institutions," Journal of Economic Literature, 53(4), 898-944.

AndReoni, J. (1988): "Privately provided public goods in a large economy: The limits of altruism," Journal of Public Economics, 35(1), 57-73.

Azrieli, Y., C. J. Chambers, and P. J. Healy (2017): "Incentives in Experiments: A Theoretical Analysis," Journal of Political Economy, conditionally accepted.

Bednar, J., Y. Chen, T. X. Liu, and S. Page (2012): "Behavioral spillovers and cognitive load in multiple games: An experimental study," Games and Economic Behavior, $74(1), 12-31$.

Belot, M., And M. SchröDer (2016): "The Spillover Effects of Monitoring: A Field Experiment," Management Science, 62(1), 37-45.

Benabou, R., And J. Tirole (2011): "Laws and Norms," NBER Working Paper Series, 17579 .

Bernasconi, M., L. Corazzini, S. Kube, and M. A. Maréchal (2009): "Two are better than one! Individuals' contributions to "unpacked" public goods," Economics Letters, 104(1), 31-33.

Bernheim, B. D. (1986): "On the voluntary and involuntary provision of public goods," American Economic Review, 151(3712), 789-793.

Bock, O., I. Baetge, And A. Nicklisch (2014): "hroot: Hamburg Registration and Organization Online Tool," European Economic Review, 71, 117 - 120.

Bowles, S., and S. Polanía-Reyes (2012): "Economic Incentives and Social Preferences: Substitutes or Complements?," Journal of Economic Literature, 50(2), 368-425.

Cason, T. N., and L. Gangadharan (2013): "Cooperation Spillovers and Price Competition in Experimental Markets," Economic Inquiry, 51(3), 1715-1730.

Cason, T. N., A. C. Savikhin, and R. M. Sheremeta (2012): "Behavioral spillovers in coordination games," European Economic Review, 56(2), 233-245.

Cettolin, E., And A. Riedl (2014): "Partial Coercion, Conditional Cooperation, and Self-Commitment in Voluntary Contributions to Public Goods," in Coercion and Social Welfare in Public Finance: Economic and Political Dimensions, ed. by S. Winer, and J. Martinez. Cambridge University Press, Cambridge, UK.

D'Adda, G., V. Capraro, and M. Tavoni (2017): "Push, don't nudge: behavioral spillovers and policy instruments," Economic Letters, 154, 92-95.

Dal Bó, E., P. Dal Bó, and E. Eyster (2017): "The Demand for Bad Policy when Voters Underappreciate Equilibrium Effects," Review of Economic Studies, forthcoming. 
Dal Bó, P., A. Foster, and L. Putterman (2010): "Institutions and Behavior: Experimental Evidence on the Effects of Democracy," American Economic Review, 100(5), 2205-2229.

Deci, E. L. (1975): Intrinsic Motivation. Plenum Press, New York.

Deci, E. L., R. Koestner, and R. M. Ryan (1999): "A Meta-Analyitc Review of Experiments Examining the Effects of Extrinsic Rewards on Intrinsic Motivation," Psychological Bulletin, 125(6), 627-628.

Deci, E. L., And R. M. Ryan (1985): Intrinsic Motivation and Self-Determination in Human Behavior. Plenum Press, New York.

Dohmen, T., A. Falk, D. Huffman, U. Sunde, J. Schupp, and G. G. Wagner (2011): "Individual Risk Attitudes: Measurement, Determinants, and Behavioral Consequences," Journal of the European Economic Association, 9(3), 522-550.

Elster, J. (1989): "Social Norms and Economic Theory," The Journal of Economic Perspective, 3(4), 99-117.

Falk, A., U. Fischbacher, and S. Gächter (2013): "Living in Two NeighborhoodsSocial Interaction Effects in the Laboratory," Economic Inquiry, 51(1), 563-578.

Fehr, E., ANd U. FischBAChER (2004): "Social norms and human cooperation.," Trends in cognitive sciences, 8(4), 185-90.

Fischbacher, U. (2007): "z-Tree: Zurich toolbox for ready-made economic experiments," Experimental Economics, 10(2), 171-178.

Fischbacher, U., And S. GÄchter (2010): "Social Preferences, Beliefs, and the Dynamics of Free Riding in Public Goods Experiments," American Economic Review, 100(1), $541-556$.

Fischbacher, U., S. Gächter, and E. Fehr (2001): "Are people conditionally cooperative ? Evidence from a public goods experiment," Economics Letters, 71(3), 397-404.

Fisman, R., and E. Miguel (2007): "Corruption, norms, and legal enforcement: Evidence from diplomatic parking tickets," Journal of Political economy, 115(6), 1020-1048.

Frederick, S. (2005): "Cognitive Reflection and Decision Making," The Journal of Economic Perspectives, 19(4), 25-42.

Frey, B. S. (1993): "Motivation as a limit to pricing," Journal of Economic Psychology, $14(4), 635-664$.

Frey, B. S., And R. Jegen (2001): "Motivation Crowding Theory," Journal of Economic Surveys, 15(5), 589-611.

Gächter, S., And E. Fehr (2000): "Cooperation and Punishment in Public Goods Experiments," American Economic Review, 90(4), 980-994. 
Gächter, S., And E. Renner (2010): "The effects of (incentivized) belief elicitation in public goods experiments," Experimental Economics, 13(3), 364-377.

Gächter, S., And J. Schulz (2016): "Intrinsic Honesty and the Prevalence of Rule Violations across Societies," Nature, 531(7595), 496-499.

Gneezy, U., S. Meier, and P. Rey-Biel (2011): "When and Why Incentives (Don't) Work to Modify Behavior," Journal of Economic Perspectives, 25(4), 191-210.

GREINER, B. (2015): "Subject pool recruitment procedures: organizing experiments with ORSEE," Journal of the Economic Science Association, 1(1), 114-125.

Grimm, V., and F. Mengel (2012): "An experiment on learning in a multiple games environment," Journal of Economic Theory, 147(6), 2220-2259.

Guiso, L., P. Sapienza, and L. Zingales (2006): "Does Culture Affect Economic Outcomes?," Journal of Economic Perspectives, 20(2), 23-48.

(2008): "Alfred Marshall: Lecture Social Capital As Good Culture," Journal of the European Economic Association, 6(2-3), 295-320.

Gürerk, O., B. Irlenbusch, and B. Rockenbach (2006): "The competitive advantage of sanctioning institutions," Science, 312(5770), 108-111.

Henrich, J., R. Boyd, S. Bowles, C. Camerer, E. Fehr, R. McElreath, and H. Gintis (2001): "In Search of Homo Economicus: Behavioral Experiments in 15 Small-Scale Societies," American Economic Review: Papers $\&$ Proceedings, 91(2), 7378.

Herrmann, B., C. Thöni, and S. GÄChter (2008): "Antisocial Punishment Across Societies," Science, 319(5868), 1362-1367.

Jehiel, P. (2005): "Analogy-based expectation equilibrium," Journal of Economic Theory, 123(2), 81-104.

KAMEI, K. (2016): "Democracy and resilient pro-social behavioral change: an experimental study," Social Choice and Welfare, 47(2), 359-378.

Kimbrough, E. O., And A. Vostroknutov (2016a): "Eliciting respect for social norms," Working Paper, pp. 1-26.

(2016b): "Norms Make Preferences Social," Journal of the European Economic Association, 14(3), 608-638.

Knez, M., and C. Camerer (2000): "Increasing Cooperation in Prisoner's Dilemmas by Establishing a Precedent of Efficiency in Coordination Games.," Organizational behavior and human decision processes, 82(2), 194-216.

Kosfeld, M., A. Okada, and A. Riedl (2009): "Institution Formation in Public Goods Games," American Economic Review, 99(4), 1335-1355. 
Krupka, E. L., and R. A. Weber (2013): "Identifying Social Norms Using Coordination Games: Why Does Dictator Game Sharing Vary?," Journal of the European Economic Association, 11(3), 495-524.

López-PÉrez, R. (2008): “Aversion to norm-breaking: A model," Games and Economic Behavior, 64(1), 237-267.

McCarter, M. W., A. Samek, and R. M. Sheremeta (2014): "Divided Loyalists or Conditional Cooperators? Creating Consensus About Cooperation in Multiple Simultaneous Social Dilemmas," Group \& Organization Management, 39(6), 744-771.

North, D. C. (1990): Institutions, Institutional Change and Economic Performance. Cambridge University Press, Cambridge, UK.

Ostrom, E. (1990): Governing the Commons - The Evolution of Institutions for Collective Action. Cambridge University Press, New York.

Ostrom, E., J. Walker, and R. Gardner (1992): "Covenants With and Without a Sword: Self-Governance is Possible," The American Political Science Review, 86(2), 404-417.

Peysakhovich, A., and D. Rand (2016): "Habits of virtue: creating norms of cooperation and defection in the laboratory," Management Science, 62(3), 631-647.

Savikhin, A. C., and R. M. Sheremeta (2013): "Simultaneous Decision-Making in Competitive and Cooperative Environments," Economic Inquiry, 51(2), 1311-1323.

Schlag, K. H., And J. J. VAn DeR Weele (2015): "A method to elicit beliefs as most likely intervals," Judgment and Decision Making, 10(5), 456-468.

SELten, R. (1967): "Die Strategiemethode zur Erforschung des eingeschränkt rationalen Verhaltens im Rahmen eines Oligopolexperiments," in Beiträge zur experimentellen Wirtschaftsforschung, ed. by H. Sauermann, vol. I, pp. 136-168. JCB Mohr (Paul Siebeck), Tübingen.

SliwkA, D. (2007): "Trust as a Signal of a Social Norm and the Hidden Costs of Incentive Schemes," American Economic Review, 97(3), 999-1012.

Sutter, M., S. Haigner, and M. G. Kocher (2010): "Choosing the Carrot or the Stick? Endogenous Institutional Choice in Social Dilemma Situations," Review of Economic Studies, 77(4), 1540-1566.

TABellini, G. (2008): "The Scope of Cooperation: Values and Incentives," The Quarterly Journal of Economics, 123(3), 905-950.

(2010): "Culture and Institutions: Economic Development in the Regions of Europe," Journal of the European Economic Association, 8(4), 677-716.

Tyran, J.-R., And L. P. Feld (2006): "Achieving Compliance when Legal Sanctions are Non-deterrent," Scandinavian Journal of Economics, 108(1), 135-156. 
Vischer, T., T. Dohmen, A. Falk, D. Huffman, J. Schupp, U. Sunde, and G. G.

WAGNer (2013): "Validating an ultra-short survey measure of patience," Economics Letters, 120(2), 142 - 145. 


\section{A Appendix}

\section{A.1 Theoretical predictions - Standard preferences}

If we assume that players are only motivated to maximize their own material payoff, the game-theoretic predictions for the one-stage game are as follows. Since the material payoff from the "PGG No Rule" is independent of the "PGG Rule", and vice versa, a player's overall utility $U_{i}$ is additively separable into payoffs from "PGG No Rule", $\pi_{i}^{L}$, and payoffs from "PGG Rule", $\pi_{i}^{R}$.

Given the contributions of all other players, the payoff $\pi_{i}^{L}$ of player $i$ from "PGG No Rule" is equal to

$$
\pi_{i}^{L}\left(g_{1}^{L}, \ldots, g_{4}^{L}\right)=w^{L}-g_{i}^{L}+a \sum_{j=1}^{4} g_{j}^{L},
$$

where $0<a<1<4 a$. The parameter $a$ models the marginal per capita return (MPCR) from contributing to the public good, $w^{L}$ is the per period endowment, and $g_{i}^{L}$ is player $i$ 's contribution to the public good in "PGG No Rule". Assumption $a<1$ implies that contributing nothing is the strictly dominant action for every player with standard preferences because every player's material payoff is maximized by contributing zero to the public good regardless of the other players' contributions.

The payoff $\pi_{i}^{R}$ of player $i$ from "PGG Rule" is equal to

$$
\pi_{i}^{R}\left(g_{1}^{R}, \ldots, g_{4}^{R}\right)= \begin{cases}w^{R}-g_{i}^{R}+a \sum_{j=1}^{4} g_{j}^{R} & \text { if } g_{i}^{R} \geq M C R \\ 0 & \text { if } g_{i}^{R}<M C R\end{cases}
$$

where $M C R$ is the minimum contribution requirement that is implemented by the institution. The $M C R$ is equal to zero in the "no institution" treatment, equal to $w^{R}$ in the "exogenous institution" treatment, and equal to the outcome of the voting process in the "endogenous institution" treatment.

Because the institution deters any material incentive to contribute less than the contribution threshold, the dominant action for every player with standard preferences is to contribute exactly the $M C R$ level in "PGG Rule". In the "no institution" treatment, the strategy profile $\left\{\left(g_{1}^{L}, g_{1}^{R}\right),\left(g_{2}^{L}, g_{2}^{R}\right),\left(g_{3}^{L}, g_{3}^{R}\right),\left(g_{4}^{L}, g_{4}^{R}\right)\right\}=\{(0,0),(0,0),(0,0),(0,0)\}$ is thus the unique Nash equilibrium of the entire game. In the "exogenous institution" treatment, the strategy profile $\left\{\left(0, w^{R}\right),\left(0, w^{R}\right),\left(0, w^{R}\right),\left(0, w^{R}\right)\right\}$ is the unique Nash equilibrium.

In the "endogenous institution" treatment, every period consists of two stages - a voting stage and a contribution stage. Therefore both voting behavior in the first stage and the contributions in the second stage are part of a player's strategy. In a subgame perfect equilibrium, players play a Nash equilibrium in every subgame. We solve the game by applying backward induction. Consider first the contribution stage. If players attempt to maximize their material payoff, they contribute nothing in the "PGG No Rule" and according to the $M C R$ in "PGG Rule". Given this behavior in the contribution stage one can derive the optimal voting behavior in the voting stage. 
Since the contributions in "PGG No Rule" are unaffected by $w^{R}$, voting can affect payoffs only in "PGG Rule". It is easily seen that everybody placing the same vote is a Nash equilibrium in the voting subgame. Since $4 a>1$, deviating to a lower vote (if possible) decreases the $M C R$ and makes the deviating player strictly worse off because all players will decrease their contributions to this lower level in stage 2. Deviating to a higher vote (if possible) does not change the $M C R$ and thus behavior in the second stage, leaving the payoff of the deviating player unaltered. In case everybody votes for 20 deviating to a lower vote makes the deviating player strictly worse off and a deviation to a higher vote is not possible. Thus, only if all other players vote for 20 , also voting for 20 is a strict best response which yields the following proposition.

PROPOSITION 1: If players have standard preferences, there exists a unique strict subgame perfect equilibrium in which all players vote to set the MCR equal to the full endowment $\left(v_{i}=w^{R} \forall i\right)$, contribute their full endowment in "PGG Rule" $\left(g_{i}^{R}=w^{R} \forall i\right)$, and contribute nothing in "PGG No Rule" $\left(g_{i}=0 \forall i\right) 27$

\footnotetext{
${ }^{27}$ Note that there exist other subgame perfect equilibria in which at least two players vote for the same $M C R v_{i}=v_{j}<w^{R}, v_{i}=\min \left\{\left(v_{i}\right)_{i \in I}\right\}$, all contribute $v_{i}=M C R$ in "PGG Rule" and 0 in "PGG No Rule". This is the case because deviating in their vote from $v_{i}$ would not change the implemented threshold (only the smallest vote counts).
} 


\section{A.2 Part II - Results}

\section{A.2.1 Regression analysis of direct and spillover effects in the "exogenous institution" treatment and the "endogenous institution" treatment}

The results regarding spillover effects are corroborated using regression analyses. Table A.1 reports the outcome of an OLS and a random effects Tobit panel regression, respectively. The independent variable is contributions to "PGG No Rule". The variable "No (constant)" indicates the "no institution" treatment as the baseline category, "Exo" ("Endo") is a dummy variable for the "exogenous institution" treatment ("endogenous institution" treatment), "Period" captures the contribution dynamics in the "no institution" treatment and the interaction variables "Exo $\times$ Period" ("Endo $\times$ Period") reflect how these dynamics differ in the two treatments with institutions in comparison to the treatment with no institution.

Table A.1: Treatment effect on contributions to "PGG No Rule"

\begin{tabular}{|c|c|c|}
\hline & $\begin{array}{c}(1) \\
\text { OLS }\end{array}$ & $\begin{array}{c}(2) \\
\text { Tobit panel }\end{array}$ \\
\hline No (constant) & $\begin{array}{c}12.208^{* * *} \\
(1.012)\end{array}$ & $\begin{array}{c}13.911^{* * *} \\
(1.219)\end{array}$ \\
\hline Exo & $\begin{array}{l}2.540^{*} \\
(1.405)\end{array}$ & $\begin{array}{l}3.886^{*} \\
(2.110)\end{array}$ \\
\hline Endo & $\begin{array}{c}0.477 \\
(1.380)\end{array}$ & $\begin{array}{c}0.690 \\
(1.633)\end{array}$ \\
\hline Period & $\begin{array}{c}-0.291^{* * *} \\
(0.048)\end{array}$ & $\begin{array}{c}-0.490^{* * *} \\
(0.074)\end{array}$ \\
\hline Exo $\times$ Period & $\begin{array}{c}0.080 \\
(0.088)\end{array}$ & $\begin{array}{l}0.105 \\
(0.105)\end{array}$ \\
\hline Endo $\times$ Period & $\begin{array}{c}0.252^{* * *} \\
(0.091) \\
\end{array}$ & $\begin{array}{c}0.475^{* * *} \\
(0.113) \\
\end{array}$ \\
\hline $\begin{array}{l}\text { Observations } \\
\text { Adjusted } R^{2}\end{array}$ & $\begin{array}{l}5440 \\
0.062\end{array}$ & 5440 \\
\hline \multicolumn{3}{|c|}{$\begin{array}{l}\text { Notes: Robust standard errors clustered on } \\
\text { part-II groups in model (1) and bootstrapped } \\
\text { standard errors }(55 \text { replications) in model }(2) \\
\text { in parentheses. }{ }^{*} p<0.10,{ }^{* *} p<0.05, \\
{ }^{* * *} p<0.01 .\end{array}$} \\
\hline
\end{tabular}

The results show that the "exogenous institution" treatment ("Exo") leads to an upward shift in the level of contributions, whereas no such effect is detected for the "endogenous institution" treatment ("Endo"). Thus, there is a spillover effect 'on impact' in the "exogenous institution" treatment but not in the "endogenous institution" treatment. Over time the effects are opposite. In the "exogenous institution" treatment the decline in contributions over the 20 periods is the same as in the "no institution" treatment ("Exo $\times$ Period" is statistically insignificant), which implies a stable spillover effect. In contrast, in the "endogenous institution" treatment, the downward dynamics observed in the 
"no institution" treatment are completely offset (coefficient of "Endo $\times$ Period" is almost equal to the negative of "Period" and statistically significant), which implies an increasing spillover effect over time.

Table A.3 in Appendix A.2.2 shows that the results reported here are robust to the inclusion of individual characteristics as control variables. Of all individual characteristics elicited in Part V, the altruism, CRT and rule-following measure have a positive and significant effect on contributions to "PGG No Rule". Average trust has a marginally significant, negative effect on contributions to "PGG No Rule".

\section{A.2.2 Contributions to "PGG No Rule" and "PGG Rule"}

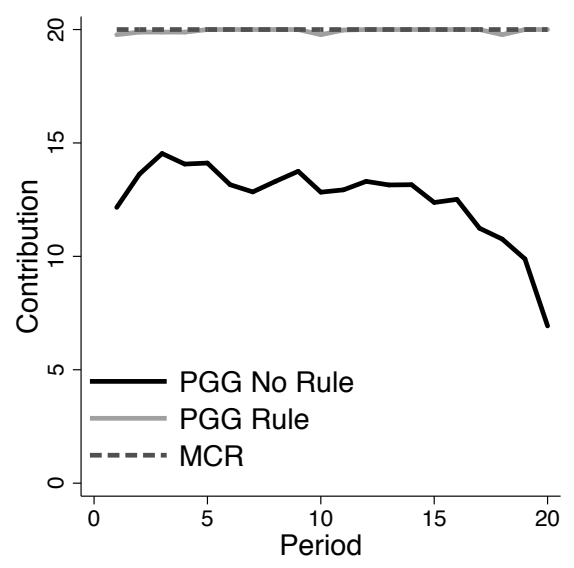

(a) Exogenous institution

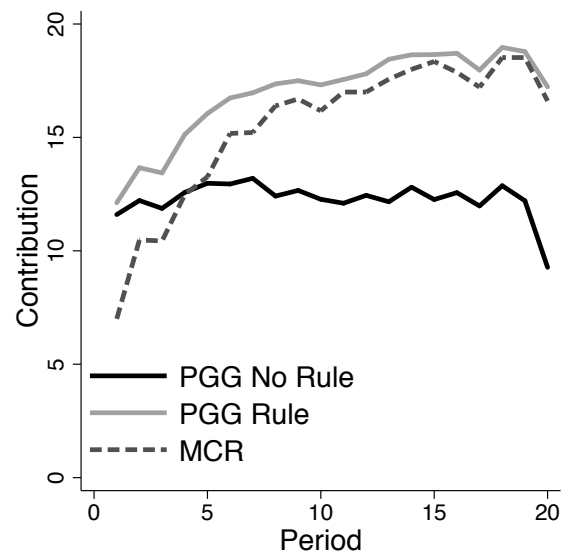

(c) Endogenous institution

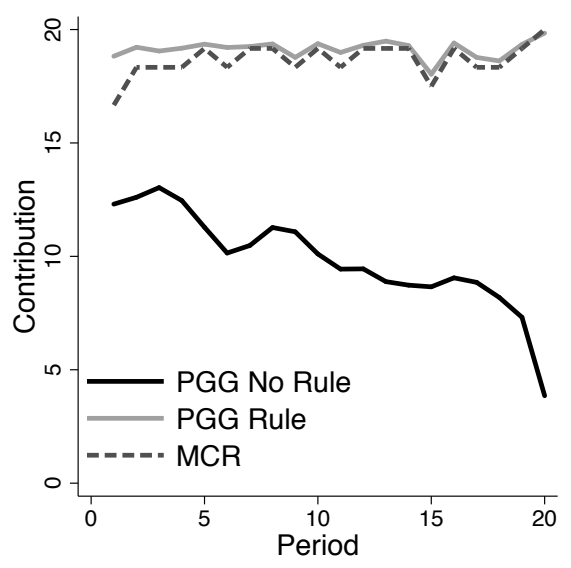

(b) Endogenous 0-20 institution

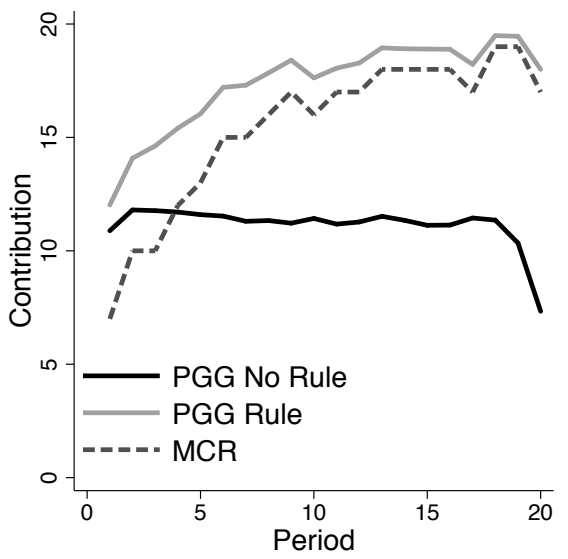

(d) Exogenous yoked institution

Figure A.1: Mean contributions under "PGG No Rule" and "PGG Rule", and MCR. 


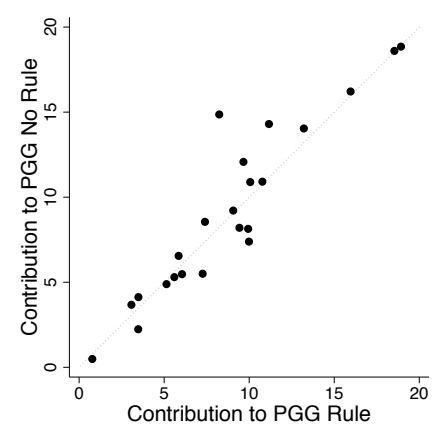

(a) No institution

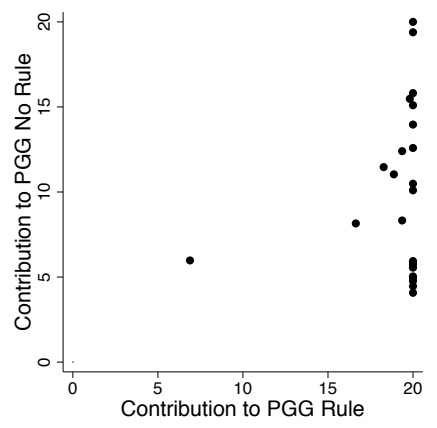

(d) Endogenous 0-20 institution

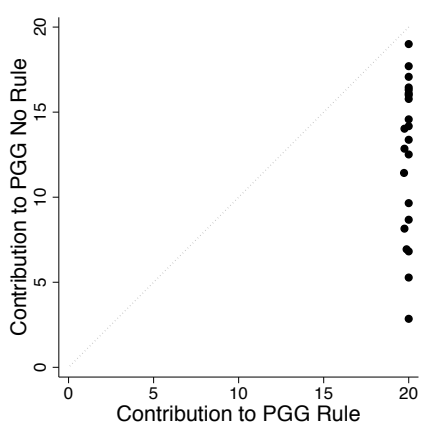

(b) Exogenous institution

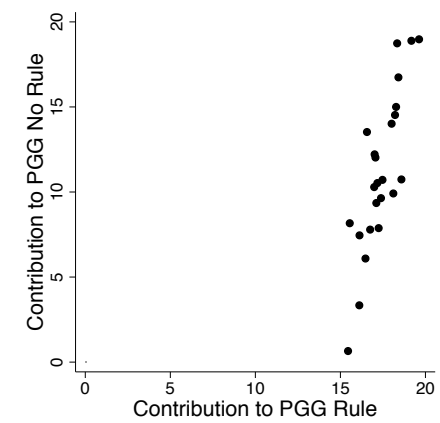

(e) Exogenous yoked institution

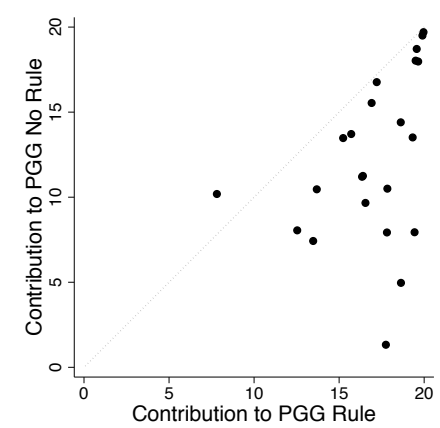

(c) Endogenous institution

Figure A.2: Average contributions to "PGG No Rule" and "PGG Rule".

Notes: Each dot shows one group's average contribution across the 20 periods of Part II to "PGG No Rule" (vertical axis) and "PGG Rule" (horizontal axis). 
Table A.2: Direct and spillover effect of institutions on contributions in the "endogenous 0-20 institution" treatment and the "exogenous yoked institution" treatment

\begin{tabular}{ll|ccccc} 
& & \multicolumn{5}{|c}{ Period } \\
& & All & $1-5$ & $6-10$ & $11-15$ & $16-20$ \\
\hline \hline & Direct effect & 10.31 & 8.52 & 9.55 & 11.27 & 11.88 \\
& $($ s.e. $)$ & $(0.56)$ & $(0.52)$ & $(0.55)$ & $(0.68)$ & $(0.56)$ \\
Endo 0-20 & [p-value] & {$[0.000]$} & {$[0.000]$} & {$[0.000]$} & {$[0.000]$} & {$[0.000]$} \\
$(\mathrm{N}=24)$ & Spillover effect & 0.71 & 1.18 & 0.38 & 0.97 & 0.31 \\
& (s.e.) & $(1.00)$ & $(0.79)$ & $(0.99)$ & $(1.16)$ & $(1.31)$ \\
& {$[\mathrm{p}$-value] } & {$[0.595]$} & {$[0.328]$} & {$[0.865]$} & {$[0.395]$} & {$[0.873]$} \\
& Relative size of & 0.07 & 0.14 & 0.04 & 0.09 & 0.03 \\
& spillover effect & & & & & \\
\hline & Direct effect & 8.56 & 3.83 & 8.03 & 10.86 & 11.50 \\
& (s.e.) & $(0.22)$ & $(0.40)$ & $(0.27)$ & $(0.17)$ & $(0.15)$ \\
Exo yoked & [p-value] & {$[0.000]$} & {$[0.000]$} & {$[0.000]$} & {$[0.000]$} & {$[0.000]$} \\
& Spillover effect & 1.98 & 0.39 & 1.13 & 3.22 & 3.18 \\
& (s.e.) & $(0.95)$ & $(0.87)$ & $(1.17)$ & $(1.14)$ & $(1.19)$ \\
& [p-value] & {$[0.142]$} & {$[0.670]$} & {$[0.551]$} & {$[0.072]$} & {$[0.053]$} \\
& Relative size of & 0.23 & 0.10 & 0.14 & 0.30 & 0.28 \\
& spillover effect & & & & & \\
\hline
\end{tabular}

Notes: For each group in the treatments, the direct (spillover) effect equals the difference between that group's average contributions to "PGG Rule" ("PGG No Rule") and the average contributions of all groups to "PGG Rule" ("PGG No Rule") in the "no institution" treatment. $p$-values are from Wilcoxon rank-sum tests comparing the group-level contributions in "PGG Rule" ("PGG No Rule") of the "exogenous institution" treatment and the "endogenous institution" treatment, respectively, to contributions in "PGG Rule" ("PGG No Rule") in the "no institution" treatment. Relative size of spillover effect is the quotient of spillover and direct effect. 
Table A.3: Treatment effect on contributions to "PGG No Rule"

\begin{tabular}{lcccccc}
\hline \hline & $(1)$ & $(2)$ & $(3)$ & $(4)$ & $(5)$ & $(6)$ \\
& OLS & OLS & OLS & Tobit panel & Tobit panel & Tobit panel \\
\hline No (constant) & $12.208^{* * *}$ & $5.730^{*}$ & 1.318 & $13.783^{* * *}$ & 2.670 & -7.596 \\
& $(1.009)$ & $(3.318)$ & $(3.082)$ & $(1.297)$ & $(5.763)$ & $(5.417)$ \\
Exo & $2.540^{*}$ & $2.810^{* *}$ & $2.572^{* *}$ & $3.771^{* *}$ & $4.283^{*}$ & $3.784^{* * *}$ \\
& $(1.401)$ & $(1.362)$ & $(1.190)$ & $(1.782)$ & $(2.229)$ & $(1.343)$ \\
Endo 0-20 & 1.106 & 1.623 & 1.544 & 2.201 & $3.204^{* *}$ & $3.025^{*}$ \\
& $(1.242)$ & $(1.178)$ & $(1.019)$ & $(1.505)$ & $(1.575)$ & $(1.656)$ \\
Endo & 0.477 & 0.909 & 0.864 & 0.669 & 1.480 & 1.413 \\
& $(1.376)$ & $(1.315)$ & $(1.192)$ & $(2.146)$ & $(1.330)$ & $(1.341)$ \\
Exo yoked & -0.213 & 0.237 & 0.235 & -1.394 & -0.576 & -0.554 \\
& $(1.497)$ & $(1.491)$ & $(1.302)$ & $(1.668)$ & $(1.640)$ & $(1.738)$ \\
Period & $-0.291^{* * *}$ & $-0.291^{* * *}$ & $-0.291^{* * *}$ & $-0.475^{* * *}$ & $-0.475^{* * *}$ & $-0.475^{* * *}$ \\
& $(0.048)$ & $(0.048)$ & $(0.048)$ & $(0.061)$ & $(0.068)$ & $(0.079)$ \\
Exo & 0.080 & 0.080 & 0.080 & 0.103 & 0.103 & 0.103 \\
$\times$ Period & $(0.088)$ & $(0.088)$ & $(0.088)$ & $(0.112)$ & $(0.113)$ & $(0.120)$ \\
Endo 0-20 & -0.038 & -0.038 & -0.038 & -0.095 & -0.096 & -0.095 \\
$\times$ Period & $(0.073)$ & $(0.073)$ & $(0.073)$ & $(0.097)$ & $(0.108)$ & $(0.120)$ \\
Endo & $0.252^{* * *}$ & $0.252^{* * *}$ & $0.252^{* * *}$ & $0.458^{* * *}$ & $0.457^{* * *}$ & $0.458^{* * *}$ \\
$\times$ Period & $(0.090)$ & $(0.091)$ & $(0.091)$ & $(0.118)$ & $(0.104)$ & $(0.101)$ \\
Exo yoked & $0.209^{* *}$ & $0.209^{* *}$ & $0.209^{* *}$ & $0.392^{* * *}$ & $0.392^{* * *}$ & $0.392^{* * *}$ \\
$\times$ Period & $(0.092)$ & $(0.092)$ & $(0.092)$ & $(0.090)$ & $(0.102)$ & $(0.121)$ \\
Controls (Part I) & No & NO & YES & NO & NO & YES \\
Controls (Part V) & No & YES & YES & NO & YES & YES \\
\hline Observations & 9280 & 9280 & 9280 & 9280 & 9280 & 9280 \\
Adj. $R^{2}$ & 0.057 & 0.106 & 0.183 & & & \\
\hline
\end{tabular}

Notes: Robust standard errors clustered on part-II groups in models (1)-(3) and bootstrapped standard errors (55 replications) in models (4)-(6) in parentheses. ${ }^{*} p<0.10,{ }^{* *} p<0.05,{ }^{* * *} p<0.01$. 
Table A.4: The effect of the $M C R$ on contributions to "PGG No Rule"

\begin{tabular}{lc}
\hline \hline & $(1)$ \\
& OLS \\
\hline$M C R$ & $\begin{array}{c}0.198^{* * *} \\
(0.064)\end{array}$ \\
Period & $-0.211^{* * *}$ \\
& $(0.039)$ \\
Constant & $11.189^{* * *}$ \\
& $(0.909)$ \\
\hline Observations & 5440 \\
Adjusted $R^{2}$ & 0.073 \\
\hline $\begin{array}{l}\text { Notes: Robust standard errors } \\
\text { clustered on part-II groups in } \\
\text { parentheses. }{ }^{*} p<0.10,{ }^{* *} p< \\
0.05,{ }^{* * *} p<0.01 .\end{array}$
\end{tabular}


Table A.5: Contributions to "PGG No Rule"

\begin{tabular}{lcc}
\hline \hline & $(1)$ Hurdle & (2) Hurdle \\
& Stage 1 & Stage 2 \\
\hline No (constant) & $1.294^{* * *}$ & $13.224^{* * *}$ \\
& $(0.192)$ & $(0.909)$ \\
Exo & -0.087 & $3.135^{* * *}$ \\
& $(0.284)$ & $(1.061)$ \\
Endo 0-20 & 0.169 & 0.585 \\
& $(0.237)$ & $(1.178)$ \\
Endo & 0.298 & -0.339 \\
& $(0.289)$ & $(1.234)$ \\
Exo yoked & 0.022 & -0.396 \\
Period & $(0.305)$ & $(1.237)$ \\
Exo $\times$ Period & $-0.052^{* * *}$ & $-0.160^{* *}$ \\
Endo 0-20 $\times$ Period & $(0.008)$ & $(0.068)$ \\
& 0.013 & 0.121 \\
Endo $\times$ Period & $(0.015)$ & $(0.085)$ \\
Exo yoked $\times$ Period & $(0.014$ & 0.044 \\
& 0.006 & $(0.100)$ \\
Observations & $(0.012)$ & $0.288^{* * *}$ \\
\hline Notes: & 0.020 & $0.195^{* *}$ \\
& $(0.016)$ & $(0.098)$ \\
\hline
\end{tabular}

Notes: The baseline category "No (constant)" is a binary variable that indicates the "no institution" treatment. The dependent variable in regression (1) is a dummy that equals 1 if contribution is positive and 0 otherwise. The dependent variable in regression (2) is the level of contributions to "PGG No Rule" conditional on a positive contribution. Stage 1 is a Probit regression; Stage 2 is a linear regression truncated at 0 . Robust standard errors (clustered on part-II groups) in parentheses. ${ }^{*} p<0.10,{ }^{* *} p<0.05,{ }^{* * *} p<0.01$. 


\section{A.2.3 Voting behavior}

Table A.6: Correlations of individual characteristics with voting decisions in period 1

\begin{tabular}{|c|c|c|}
\hline & $\overline{\text { Vote }}$ & $\overline{\mathrm{N}}$ \\
\hline Part I - Uncond. contr. & $\begin{array}{c}0.237^{* *} \\
(0.023)\end{array}$ & 92 \\
\hline Part I - Belief & $\begin{array}{c}0.270^{* * *} \\
(0.009)\end{array}$ & 92 \\
\hline Part I - Avg. cond. contr. & $\begin{array}{c}0.148 \\
(0.159)\end{array}$ & 92 \\
\hline Risk & $\begin{array}{c}0.047 \\
(0.654)\end{array}$ & 92 \\
\hline Patience & $\begin{array}{c}0.058 \\
(0.581)\end{array}$ & 92 \\
\hline Altruism & $\begin{array}{c}0.137 \\
(0.190)\end{array}$ & 92 \\
\hline Avg. pos. reciprocity & $\begin{array}{l}-0.006 \\
(0.949)\end{array}$ & 92 \\
\hline Avg. neg. reciprocity & $\begin{array}{l}-0.127 \\
(0.226)\end{array}$ & 92 \\
\hline Avg. trust & $\begin{array}{c}-0.012 \\
(0.913)\end{array}$ & 92 \\
\hline CRT & $\begin{array}{l}-0.027 \\
(0.832)\end{array}$ & 66 \\
\hline RFT & $\begin{array}{c}-0.116 \\
(0.270)\end{array}$ & 92 \\
\hline Age & $\begin{array}{c}-0.021 \\
(0.846)\end{array}$ & 92 \\
\hline Female & $\begin{array}{c}-0.197^{*} \\
(0.060)\end{array}$ & 92 \\
\hline Business \& economics & $\begin{array}{c}0.034 \\
(0.750) \\
\end{array}$ & 92 \\
\hline
\end{tabular}

Notes: The table reports Spearman's rank correlation coefficients. P-values in parentheses. CRT has 66 observations only because we exclude the 26 subjects who indicated that they saw the CRT questions before. ${ }^{*} p<0.10,{ }^{* *} p<0.05,{ }^{* * *} p<0.01$. 


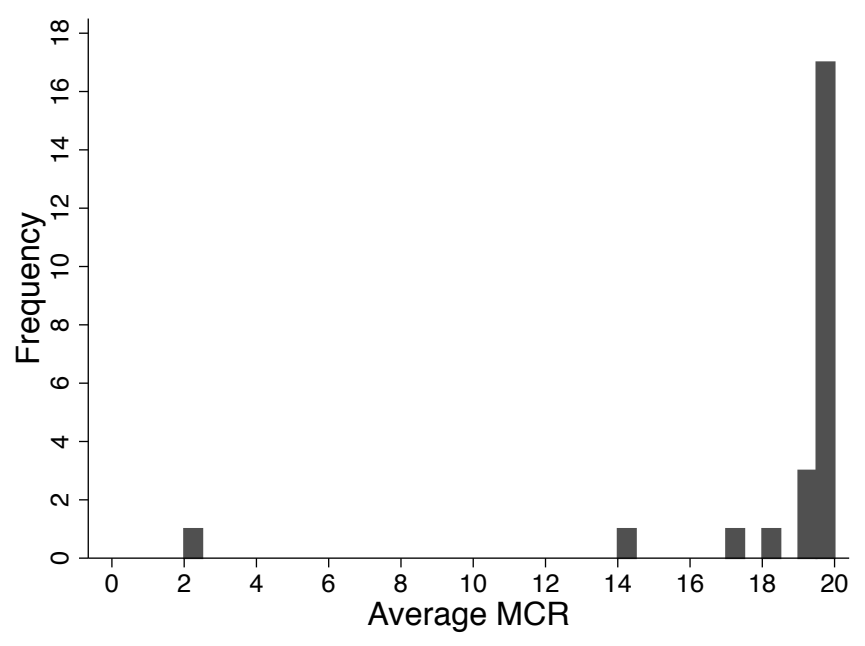

Figure A.3: Frequency of implemented MCR's (group averages) in the "endogenous 0-20 institution" treatment.

Table A.7: Contributions to "PGG No Rule" for different voting outcomes in the "endogenous 0-20 institution" treatment

\begin{tabular}{c|ccccc} 
& \multicolumn{5}{|c}{ Votes for a $M C R$ of 20} \\
& 0 & 1 & 2 & 3 & 4 \\
\hline \hline Number of periods & 3 & 6 & 23 & 91 & 357 \\
Avg. contribution to "PGG No Rule" & 4.00 & 5.88 & 8.59 & 9.52 & 10.14 \\
..of those who voted for 20 & - & 3.5 & 10.11 & 10.47 & 10.14 \\
..of those who voted for 0 & 4.00 & 6.67 & 7.07 & 6.68 & - \\
\hline
\end{tabular}




\section{A.2.4 Evidence against imitation}

In this part, we test whether our findings are driven by subjects who simply copied their decisions in "PGG Rule" to "PGG No Rule". If that would be the case, then it could explain the treatment effects that we find, because, due to the $M C R$, contributions to "PGG Rule" are higher in the "exogenous institution" treatment and the "endogenous institution" treatment than in the "no institution" treatment.

First, we focus on cases in which subjects inserted identical contribution levels in "PGG No Rule" and "PGG Rule". In the "no institution" treatment, we find that this is the case in 62.77 percent of observations. In the "exogenous institution" treatment and the "endogenous institution" treatment, the frequency of such cases is significantly lower (34.20 percent and 37.88 percent, respectively; Fisher's exact test, $p<0.001$ and $p<0.001$, respectively). However, contributing the same amount to "PGG No Rule" and "PGG Rule" is not necessarily evidence of imitation. Indeed, for many preference types, a person with identical beliefs about others' behavior across the two games has no reason to contribute anything but identical values.Nevertheless, imitation by copying contributions may occur in those relatively infrequent cases where contributions are identical.

To determine whether the treatments have an effect only because subjects copy the $M C R$ in "PGG No Rule", we consider those cases in the "endogenous institution" treatment in which a $M C R$ above 0 but below 20 was implemented. Only for those cases it is fairly certain that, if subjects imitated the $M C R$ in "PGG No Rule", it is deliberate and not because they hit the corner of 0 or 20. Out of 868 cases (individual observations) in which a $M C R$ above 0 and below 20 was implemented, the contributions to "PGG No Rule" were identical to the contributions to "PGG Rule" in 199 cases (22.93 percent) and were identical to the $M C R$ in 86 cases (9.91 percent). Thus, in maximally 10 percent of all cases may have subjects mirrored the $M C R$ deliberately. Excluding those observations and only considering a $M C R$ between 0 and 20, we still find a highly significant positive correlation between the implemented $M C R$ and contributions to "PGG No Rule" (Spearman's rho, $\rho=0.181, p<0.001$ ) 28 Thus, we don't find evidence that such a pure imitation effect is driving the treatment effect.

Second, we test whether two proxy variables, which arguably measure proneness to simply (but perhaps imperfectly) imitating the $M C R$ in "PGG No Rule", explain contributions to "PGG No Rule". These two variables are i) a binary variable that indicates whether the contribution to "PGG Rule" was submitted first, and ii) a continuous variables that measures the time span in between the contribution submission to "PGG Rule" and "PGG No Rule". We assume that subjects who submit their contribution decision for "PGG Rule" first and let little time pass in between the two decisions are more prone to simply (but possibly imperfectly) imitate the $M C R$.

Averaged over all periods, the proportion of subjects who submitted their contribution decision for "PGG Rule" before their decision for "PGG No Rule" is somewhat higher in the "exogenous institution" treatment (34.55 percent) and the "endogenous institution"

\footnotetext{
${ }^{28}$ When taking individual averages over all relevant periods that fit the criteria, the results remain the same (Spearman's rho, $\rho=0.299, p=0.005$ ).
} 
treatment (37.17 percent) than in the "no institution" treatment (30.49 percent). Furthermore, in the very first period, the differences are even more pronounced (26.14 percent in the "exogenous institution" treatment and 31.52 percent in the "endogenous institution" treatment vs 15.22 percent in the "no institution" treatment). On the other hand, the time between the submissions is lower in the "no institution" treatment than in both the "exogenous institution" treatment and the "endogenous institution" treatment (1.54 seconds vs 2.17 and 2.43 seconds, respectively).

When we regress the decision to submit first in "PGG Rule" on the absolute difference in contributions between "PGG No Rule" and "PGG Rule" (see column (1) of Table A.8), we find that there is no effect in the "no institution" treatment and the "exogenous institution" treatment, but a significantly positive effect in the "endogenous institution" treatment. Thus, submitting the contribution to "PGG Rule" first significantly increases the difference in contributions between the "PGG Rule" and "PGG No Rule" in the "endogenous institution" treatment compared to the "no institution" treatment, which is the opposite of what one would expect in case of an imitation effect.

When regressing the time span between the submissions of contributions on the absolute difference in contributions in the two games (see column (2) of Table A.8), we do not find any significant effect.

Finally, when regressing all interactions on the absolute difference in contribution between "PGG No Rule" and "PGG Rule" (see column (3) of Table A.8), we find that, in the "no institution" treatment, the difference in contributions significantly decreases the shorter is the difference in time between the two decisions, but only if one decides about "PGG Rule" first. Thus, this looks like an imitation effect. However, the effect is completely counteracted in the "exogenous institution" treatment and the "endogenous institution" treatment. Thus, to summarize, we don't find any evidence that imitation effects could explain our results. 
Table A.8: Influence of decision sequence and time on the difference in contributions

\begin{tabular}{|c|c|c|c|}
\hline & $\begin{array}{c}(1) \\
\text { OLS }\end{array}$ & $\begin{array}{c}(2) \\
\text { OLS }\end{array}$ & $\begin{array}{c}(3) \\
\text { OLS }\end{array}$ \\
\hline Period & $\begin{array}{c}0.135^{* * *} \\
(0.039)\end{array}$ & $\begin{array}{c}0.140^{* * *} \\
(0.038)\end{array}$ & $\begin{array}{c}0.138^{* * *} \\
(0.038)\end{array}$ \\
\hline No (constant) & $\begin{array}{c}0.563 \\
(0.507)\end{array}$ & $\begin{array}{c}0.426 \\
(0.507)\end{array}$ & $\begin{array}{c}0.468 \\
(0.503)\end{array}$ \\
\hline Exo & $\begin{array}{c}5.328^{* * *} \\
(1.090)\end{array}$ & $\begin{array}{c}5.470^{* * *} \\
(1.023)\end{array}$ & $\begin{array}{c}5.306^{* * *} \\
(1.099)\end{array}$ \\
\hline Endo & $\begin{array}{c}3.000^{* * *} \\
(0.919)\end{array}$ & $\begin{array}{c}3.447^{* * *} \\
(1.070)\end{array}$ & $\begin{array}{c}2.898^{* * *} \\
(0.993)\end{array}$ \\
\hline Right first & $\begin{array}{l}-0.039 \\
(0.295)\end{array}$ & & $\begin{array}{c}-0.781^{*} \\
(0.408)\end{array}$ \\
\hline Right first $\times$ Exo & $\begin{array}{c}0.437 \\
(0.830)\end{array}$ & & $\begin{array}{c}1.279 \\
(0.896)\end{array}$ \\
\hline Right first $\times$ Endo & $\begin{array}{l}1.362^{*} \\
(0.764)\end{array}$ & & $\begin{array}{l}2.182^{* *} \\
(0.964)\end{array}$ \\
\hline Time diff & & $\begin{array}{c}0.043 \\
(0.043)\end{array}$ & $\begin{array}{c}0.034 \\
(0.036)\end{array}$ \\
\hline Time diff $\times$ Exo & & $\begin{array}{l}-0.009 \\
(0.060)\end{array}$ & $\begin{array}{c}0.010 \\
(0.064)\end{array}$ \\
\hline Time diff $\times$ Endo & & $\begin{array}{c}0.008 \\
(0.085)\end{array}$ & $\begin{array}{c}0.030 \\
(0.084)\end{array}$ \\
\hline Right first $\times$ Time diff & & & $\begin{array}{c}0.641^{* * *} \\
(0.226)\end{array}$ \\
\hline Right first $\times$ Time diff $\times$ Exo & & & $\begin{array}{c}-0.694^{* * *} \\
(0.244)\end{array}$ \\
\hline Right first $\times$ Time diff $\times$ Endo & & & $\begin{array}{c}-0.672^{* * *} \\
(0.250)\end{array}$ \\
\hline Observations & 5440 & 5440 & 5440 \\
\hline Adjusted $R^{2}$ & 0.128 & 0.125 & 0.128 \\
\hline \multicolumn{4}{|c|}{$\begin{array}{l}\text { Notes: The dependent variable is the absolute difference in contributions } \\
\text { between "PGG No Rule" and "PGG Rule". "Right first" is a binary vari- } \\
\text { able that is } 1 \text { if the subject submitted his decision for "PGG Rule" first and } \\
\text { zero otherwise. "Time diff" is the time difference, in seconds, between the } \\
\text { first and the second submission of contribution decision. Robust standard } \\
\text { errors (clustered on part-II groups) in parentheses. }{ }^{*} p<0.10,{ }^{* *} p<0.05 \text {, } \\
{ }^{* * *} p<0.01 \text {. }\end{array}$} \\
\hline
\end{tabular}




\section{A.2.5 Potential channels}

Table A.9: Rule-following channel and Social Heuristics Hypothesis

\begin{tabular}{|c|c|c|}
\hline & $\begin{array}{c}(1) \\
\text { OLS }\end{array}$ & $\begin{array}{c}(2) \\
\text { OLS }\end{array}$ \\
\hline No (constant) & $\begin{array}{c}11.701^{* * *} \\
(1.242)\end{array}$ & $\begin{array}{c}9.293^{* * *} \\
(1.298)\end{array}$ \\
\hline Exo & $\begin{array}{c}2.062 \\
(1.872)\end{array}$ & $\begin{array}{c}5.321^{* * *} \\
(1.789)\end{array}$ \\
\hline Endo 0-20 & $\begin{array}{c}0.482 \\
(1.558)\end{array}$ & $\begin{array}{c}1.677 \\
(1.625)\end{array}$ \\
\hline Endo & $\begin{array}{c}1.123 \\
(1.653)\end{array}$ & $\begin{array}{c}2.652 \\
(1.748)\end{array}$ \\
\hline Exo yoked & $\begin{array}{l}-0.995 \\
(1.841)\end{array}$ & $\begin{array}{c}1.514 \\
(1.732)\end{array}$ \\
\hline Period & $\begin{array}{c}-0.291^{* * *} \\
(0.048)\end{array}$ & $\begin{array}{c}-0.280^{* * *} \\
(0.061)\end{array}$ \\
\hline Exo $\times$ Period & $\begin{array}{c}0.080 \\
(0.088)\end{array}$ & $\begin{array}{c}0.062 \\
(0.096)\end{array}$ \\
\hline Endo $0-20 \times$ Period & $\begin{array}{l}-0.038 \\
(0.073)\end{array}$ & $\begin{array}{l}-0.072 \\
(0.082)\end{array}$ \\
\hline Endo $\times$ Period & $\begin{array}{c}0.252^{* * *} \\
(0.091)\end{array}$ & $\begin{array}{l}0.210^{* *} \\
(0.106)\end{array}$ \\
\hline Exo yoked $\times$ Period & $\begin{array}{l}0.209^{* *} \\
(0.092)\end{array}$ & $\begin{array}{l}0.194^{*} \\
(0.100)\end{array}$ \\
\hline $\mathrm{RFT}$ & $\begin{array}{c}0.037 \\
(0.038)\end{array}$ & \\
\hline Exo $\times$ RFT & $\begin{array}{c}0.036 \\
(0.066)\end{array}$ & \\
\hline Endo $0-20 \times \mathrm{RFT}$ & $\begin{array}{c}0.046 \\
(0.056)\end{array}$ & \\
\hline Endo $\times \mathrm{RFT}$ & $\begin{array}{l}-0.047 \\
(0.059)\end{array}$ & \\
\hline Exo yoked $\times \mathrm{RFT}$ & $\begin{array}{c}0.062 \\
(0.061)\end{array}$ & \\
\hline CRT & & $\begin{array}{c}1.636^{* * *} \\
(0.467)\end{array}$ \\
\hline Exo $\times$ CRT & & $\begin{array}{c}-1.462^{* *} \\
(0.666)\end{array}$ \\
\hline Endo $0-20 \times \mathrm{CRT}$ & & $\begin{array}{l}-0.390 \\
(0.728)\end{array}$ \\
\hline Endo $\times$ CRT & & $\begin{array}{l}-1.152 \\
(0.925)\end{array}$ \\
\hline Exo yoked $\times \mathrm{CRT}$ & & $\begin{array}{l}-0.842 \\
(0.570)\end{array}$ \\
\hline Observations & 9280 & 7260 \\
\hline Adj. $R^{2}$ & 0.069 & 0.087 \\
\hline \multicolumn{3}{|c|}{$\begin{array}{l}\text { Notes: The independent variable is contributions to } \\
\text { "PGG No Rule". There are fewer observation in } \\
\text { model (2) as we excluded those subjects that indi- } \\
\text { cated that they had seen the CRT questions before. } \\
\text { Robust standard errors (clustered on part-II groups) } \\
\text { in parentheses. }{ }^{*} p<0.10,{ }^{* *} p<0.05,{ }^{* * *} p<0.01\end{array}$} \\
\hline
\end{tabular}




\section{A.3 Part I, III, IV - Results}

Table A.10: Unconditional contributions

\begin{tabular}{|c|c|c|c|c|c|c|}
\hline & Part I & Part III & Part IV & $\begin{array}{c}\text { p-value } \\
\text { (I vs. III) }\end{array}$ & $\begin{array}{c}\text { p-value } \\
\text { (I vs. IV) }\end{array}$ & $\begin{array}{c}\text { p-value } \\
\text { (III vs. IV) }\end{array}$ \\
\hline $\begin{array}{l}\text { No inst. } \\
(\mathrm{N}=23)\end{array}$ & $\begin{array}{l}11.37 \\
(.60)\end{array}$ & $\begin{array}{c}6.95 \\
(1.01)\end{array}$ & $\begin{array}{l}8.65 \\
(.88)\end{array}$ & 0.000 & 0.002 & 0.005 \\
\hline $\begin{array}{l}\text { Exo. inst. } \\
(\mathrm{N}=22)\end{array}$ & $\begin{array}{l}11.40 \\
(.67)\end{array}$ & $\begin{array}{l}10.40 \\
(.85)\end{array}$ & $\begin{array}{l}10.30 \\
(.75)\end{array}$ & 0.398 & 0.168 & 0.961 \\
\hline $\begin{array}{l}\text { Endo. } 0-20 \text { inst. } \\
\qquad(\mathrm{N}=24)\end{array}$ & $\begin{array}{l}11.53 \\
(.68)\end{array}$ & $\begin{array}{l}8.42 \\
(.95)\end{array}$ & $\begin{array}{l}9.06 \\
(.81)\end{array}$ & 0.001 & 0.002 & 0.126 \\
\hline $\begin{array}{l}\text { Endo. inst. } \\
\quad(\mathrm{N}=23)\end{array}$ & $\begin{array}{l}11.53 \\
(.61)\end{array}$ & $\begin{array}{l}12.03 \\
(1.05)\end{array}$ & $\begin{array}{l}11.37 \\
(.87)\end{array}$ & 0.553 & 0.738 & 0.212 \\
\hline $\begin{array}{l}\text { Exo. yoked inst. } \\
(\mathrm{N}=24)\end{array}$ & $\begin{array}{l}11.75 \\
(.47)\end{array}$ & $\begin{array}{l}10.35 \\
(.97) \\
\end{array}$ & $\begin{array}{l}10.09 \\
(.84) \\
\end{array}$ & 0.086 & 0.036 & 0.406 \\
\hline $\begin{array}{c}\text { p-value } \\
\text { (No vs. Exo) }\end{array}$ & 0.901 & 0.009 & $\overline{0.173}$ & & & \\
\hline $\begin{array}{c}\text { p-value } \\
\text { (No vs. Endo 0-20) }\end{array}$ & 0.966 & 0.268 & 0.765 & & & \\
\hline $\begin{array}{c}\text { p-value } \\
\text { (No vs. Endo) }\end{array}$ & 0.783 & 0.002 & 0.017 & & & \\
\hline $\begin{array}{c}\text { p-value } \\
\text { (No vs. Exo yoked) }\end{array}$ & 0.693 & 0.012 & 0.145 & & & \\
\hline $\begin{array}{c}\text { p-value } \\
\text { (Exo vs. Endo 0-20) }\end{array}$ & 0.921 & 0.082 & 0.198 & & & \\
\hline $\begin{array}{c}\text { p-value } \\
\text { (Endo vs. Exo yoked) }\end{array}$ & 0.924 & 0.183 & 0.205 & & & \\
\hline $\begin{array}{c}\text { p-value } \\
\text { (Exo vs. Endo })\end{array}$ & 0.750 & 0.195 & 0.159 & & & \\
\hline
\end{tabular}

Notes: Numbers in brackets are standard errors. Across treatments: p-values from Wilcoxon rank-sum tests. Within treatments: p-values from Wilcoxon signed-rank tests. 
Table A.11: Midpoint of belief interval

\begin{tabular}{|c|c|c|c|c|c|c|}
\hline & Part I & Part III & Part IV & $\begin{array}{l}\text { p-value } \\
\text { (I vs. III) }\end{array}$ & $\begin{array}{l}\text { p-value } \\
\text { (I vs. IV) }\end{array}$ & $\begin{array}{l}\text { p-value } \\
\text { (III vs. IV) }\end{array}$ \\
\hline $\begin{array}{l}\text { No inst. } \\
(\mathrm{N}=23)\end{array}$ & $\begin{array}{l}11.88 \\
(.38)\end{array}$ & $\begin{array}{l}8.14 \\
(.94)\end{array}$ & $\begin{array}{l}9.78 \\
(.70)\end{array}$ & 0.000 & 0.002 & 0.002 \\
\hline $\begin{array}{l}\text { Exo. inst. } \\
(\mathrm{N}=22)\end{array}$ & $\begin{array}{l}11.98 \\
(.44)\end{array}$ & $\begin{array}{l}11.41 \\
(.78)\end{array}$ & $\begin{array}{l}11.74 \\
(.59)\end{array}$ & 0.987 & 0.871 & 0.291 \\
\hline $\begin{array}{l}\text { Endo. } 0-20 \text { inst. } \\
\qquad(\mathrm{N}=24)\end{array}$ & $\begin{array}{l}12.07 \\
(.37)\end{array}$ & $\begin{array}{l}9.82 \\
(.79)\end{array}$ & $\begin{array}{l}11.09 \\
(.58)\end{array}$ & 0.010 & 0.045 & 0.004 \\
\hline $\begin{array}{l}\text { Endo. inst. } \\
\quad(\mathrm{N}=23)\end{array}$ & $\begin{array}{l}11.42 \\
(.37)\end{array}$ & $\begin{array}{l}13.02 \\
(.66)\end{array}$ & $\begin{array}{l}11.96 \\
(.52)\end{array}$ & 0.018 & 0.260 & 0.005 \\
\hline $\begin{array}{l}\text { Exo. yoked inst. } \\
(\mathrm{N}=24)\end{array}$ & $\begin{array}{l}11.80 \\
(.35)\end{array}$ & $\begin{array}{l}10.99 \\
(.77)\end{array}$ & $\begin{array}{l}11.04 \\
(.50)\end{array}$ & 0.265 & 0.067 & 0.668 \\
\hline $\begin{array}{c}\text { p-value } \\
\text { (No vs. Exo) }\end{array}$ & 0.892 & 0.012 & 0.047 & & & \\
\hline $\begin{array}{c}\text { p-value } \\
\text { (No vs. Endo 0-20) }\end{array}$ & 0.725 & 0.233 & 0.198 & & & \\
\hline $\begin{array}{c}\text { p-value } \\
\text { (No vs. Endo) }\end{array}$ & 0.422 & 0.000 & 0.013 & & & \\
\hline $\begin{array}{c}\text { p-value } \\
\text { (No vs. Exo yoked) }\end{array}$ & 0.966 & 0.029 & 0.108 & & & \\
\hline $\begin{array}{c}\text { p-value } \\
\text { (Exo vs. Endo 0-20) }\end{array}$ & 0.973 & 0.124 & 0.468 & & & \\
\hline $\begin{array}{c}\text { p-value } \\
\text { (Endo vs. Exo yoked) }\end{array}$ & 0.469 & 0.047 & 0.106 & & & \\
\hline $\begin{array}{c}\text { p-value } \\
\text { (Exo vs. Endo) }\end{array}$ & 0.346 & 0.196 & 0.708 & & & \\
\hline
\end{tabular}

Notes: Numbers in brackets are standard errors. Across treatments: p-values from Wilcoxon rank-sum tests. Within treatments: p-values from Wilcoxon signed-rank tests. 
Table A.12: Avg. conditional contributions

\begin{tabular}{|c|c|c|c|c|c|c|}
\hline & Part I & Part III & Part IV & $\begin{array}{c}\text { p-value } \\
\text { (I vs. III) }\end{array}$ & $\begin{array}{c}\text { p-value } \\
\text { (I vs. IV) }\end{array}$ & $\begin{array}{c}\text { p-value } \\
\text { (III vs. IV) }\end{array}$ \\
\hline $\begin{array}{l}\text { No inst. } \\
(\mathrm{N}=23)\end{array}$ & $\begin{array}{l}7.86 \\
(.50)\end{array}$ & $\begin{array}{l}5.63 \\
(.54)\end{array}$ & $\begin{array}{l}5.76 \\
(.48)\end{array}$ & 0.000 & 0.000 & 0.867 \\
\hline $\begin{array}{l}\text { Exo. inst. } \\
(\mathrm{N}=22)\end{array}$ & $\begin{array}{l}8.48 \\
(.45)\end{array}$ & $\begin{array}{l}7.60 \\
(.51)\end{array}$ & $\begin{array}{l}7.64 \\
(.65)\end{array}$ & 0.064 & 0.127 & 0.948 \\
\hline $\begin{array}{l}\text { Endo. } 0-20 \text { inst. } \\
\qquad(\mathrm{N}=24)\end{array}$ & $\begin{array}{l}7.89 \\
(.30)\end{array}$ & $\begin{array}{l}6.30 \\
(.54)\end{array}$ & $\begin{array}{l}6.24 \\
(.51)\end{array}$ & 0.002 & 0.002 & 0.558 \\
\hline $\begin{array}{l}\text { Endo. inst. } \\
\quad(\mathrm{N}=23)\end{array}$ & $\begin{array}{l}7.95 \\
(.35)\end{array}$ & $\begin{array}{l}7.69 \\
(.35)\end{array}$ & $\begin{array}{l}7.20 \\
(.45)\end{array}$ & 0.412 & 0.094 & 0.023 \\
\hline $\begin{array}{l}\text { Exo. yoked inst. } \\
(\mathrm{N}=24)\end{array}$ & $\begin{array}{l}7.75 \\
(.47)\end{array}$ & $\begin{array}{l}6.41 \\
(.57)\end{array}$ & $\begin{array}{l}6.14 \\
(.53)\end{array}$ & 0.012 & 0.002 & 0.415 \\
\hline $\begin{array}{c}\text { p-value } \\
\text { (No vs. Exo) }\end{array}$ & 0.414 & 0.005 & 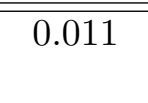 & & & \\
\hline $\begin{array}{c}\text { p-value } \\
\text { (No vs. Endo 0-20) }\end{array}$ & 0.949 & 0.431 & 0.734 & & & \\
\hline $\begin{array}{c}\text { p-value } \\
\text { (No vs. Endo) }\end{array}$ & 0.861 & 0.008 & 0.024 & & & \\
\hline $\begin{array}{c}\text { p-value } \\
\text { (No vs. Exo yoked) }\end{array}$ & 0.915 & 0.302 & 0.431 & & & \\
\hline $\begin{array}{c}\text { p-value } \\
\text { (Exo vs. Endo 0-20) }\end{array}$ & 0.276 & 0.077 & 0.065 & & & \\
\hline $\begin{array}{c}\text { p-value } \\
\text { (Endo vs. Exo yoked) }\end{array}$ & 0.924 & 0.101 & 0.069 & & & \\
\hline $\begin{array}{c}\text { p-value } \\
\text { (Exo vs. Endo) }\end{array}$ & 0.401 & 0.991 & 0.829 & & & \\
\hline
\end{tabular}

Notes: Numbers in brackets are standard errors. Across treatments: p-values from Wilcoxon rank-sum tests. Within treatments: p-values from Wilcoxon signed-rank tests. 


\section{A.4 Part V - Questions}

- Risk question (SOEP, 2004, 2006, 2008, 2009)

How do you see yourself: Are you generally a person who is fully prepared to take risks or do you try to avoid taking risks?

Please tick a box on the scale where the value 0 means: "not at all willing to take risks" and the value 10 means: "very willing to take risks".

- Patience question (SOEP, 2008)

How would you describe yourself: Are you generally an impatient person, or someone who always shows great patience?

Please tick a box on the scale where the value 0 means: "very impatient" and the value 10 means: "very patient".

- Altruism question (SOEP, 2004, 2008)

Is it important for you to be there for others?

Please tick a box on the scale where the value 0 means: "not at all important" and the value 4 means: "very important".

- Reciprocity question (SOEP, 2005)

For the questions below, please tick a box on the scale, where the value 1 means: "does not apply to me at all" and the value 7 means: "applies to me perfectly".

(1) If someone does me a favor, I am prepared to return it.

(2) If I suffer a serious wrong, I will take revenge as soon as possible, no matter what the cost.

(3) If somebody puts me in a difficult position, I will do the same to him/her.

(4) I go out of the way to help somebody who has been kind to me before.

(5) If somebody offends me, I will offend him/her back.

(6) I am ready to undergo personal costs to help somebody who helped me before.

- Trust question (SOEP, 2003, 2008)

For the questions below, please tick a box on the scale, where the value 1 means: "totally disagree" and the value 4 means: "totally agree".

On the whole one can trust people.

Nowadays one can't rely on anyone.

If one is dealing with strangers, it is better to be careful before one can trust them. 


\section{B Experimental instructions}

\section{B.1 Instructions for Part I}

General instructions

Welcome to this experiment.

Please read this first page of the instructions carefully on your own. We will then read the rest of the instructions aloud in front of all participants.

In the experiment you can earn a considerable amount of money in addition to the $\mathbf{1 0}$ Swiss francs that you receive for showing up on time. How much you earn will depend on your own decisions and those of the other participants. It is thus very important that you read the instructions carefully. If you have any questions please do not ask aloud but raise your hand.

During the experiment, speaking with the other participants and the use of mobile phones are not allowed. Violation of these rules can lead to exclusion from the experiment and loss of all associated earnings.

During the experiment, we will refer to earnings in Experimental Currency Units, or ECU. Your entire income will first be calculated in ECU. The ECU you earn during the experiment will be converted to Swiss francs at the end of the experiment, according to the following conversion rate:

\section{$100 \mathrm{ECU}=3 \mathrm{CHF}$}

At the end of today's experiment, you will receive these earnings plus the show-up payment of 10 Swiss francs in cash.

At no point, during or after the experiment, will you learn the identities of the people with whom you interact during the experiment, nor will these people learn your identity. 


\section{The Experiment}

The experiment consists of several parts. At the beginning of each part you will receive instructions that explain that part of the experiment. The earnings that you will receive for the experiment consist of the sum of your earnings in the individual parts in addition to the fee for showing up.

\section{Part I}

\section{Group Membership}

At the beginning of Part I, the computer will assign you at random to a group consisting of four participants. All interactions during Part I take place within the group to which you are assigned.

Part I consists of two phases. In both phases you will make decisions related to a basic task. Before explaining the two phases in more detail, we first explain the basic task to you.

\section{The Basic Task}

Each of the four members of your group is endowed with 20 tokens. Each member of the group decides how many of the 20 tokens to put in a private account and how many to contribute to a group account. Any tokens you put in the private account cannot be contributed to the group account and vice versa. You can earn income from the private account as well as from the group account.

\section{Your income from the private account}

For each token you put in your private account you earn an income of one ECU. Nobody except you earns anything from tokens you put in your private account.

EXAMPLE: If you put 6 tokens in your private account, you earn 6 ECU from the private account. 


\section{Your income from the group account}

For each token you contribute to the group account you and the other three group members each receive 0.5 ECU. Note that you will also earn income from the tokens that other group members contribute to the group account. For each group member the income from the group account will be determined as follows:

\section{Each group member's income from the group account}

\section{$=0.5 *$ sum of all tokens contributed to the group account}

Put differently, the total number of tokens in the group account will be doubled and then equally distributed among all four group members. This yields, for each group member, 0.5 times the total number of tokens contributed. Suppose you contribute one token to the group account. The sum of tokens in the group account would then rise by one token. Your income from the group account would, thus, rise by $0.5 * 1=0.5 \mathrm{ECU}$. The income of each other group member would also rise by $0.5 \mathrm{ECU}$. So, contributing one token to the group account generates total income for the group of $4 * 0.5 \mathrm{ECU}=2 \mathrm{ECU}$.

EXAMPLE: If the sum of tokens in the group account is 60 tokens, then you and all other group members each earn an income of $0.5 * 60=30$ ECU from the group account. The total income for the group from the group account is $4 * 30 \mathrm{ECU}=120 \mathrm{ECU}$.

\section{Your total income}

Your total income equals the sum of your income from the private account and your income from the group account.

Total income $=$

Income from the private account + Income from the group account $=$

$(20$ - tokens you contribute to the group account $)+(0.5 *$ sum of tokens in the group account)

Part I of the experiment consists of two phases. In the first phase you are asked to indicate your belief about how much the other three members of your group will, on average, contribute to the group account in a task identical to the one just described. In the second phase you are asked to decide how much you contribute to the group account in a task identical to the one just described. 


\section{a) Phase 1: Estimates of other group members' average contributions}

In Phase 1, we ask you to estimate how many tokens the other three members in your group will, on average, contribute to the group account in Phase 2. Remember that each member has an endowment of 20 tokens and can contribute any amount from 0 to 20 tokens to the group account. Specifically, we ask you to provide a range of values that you believe will contain the average number of tokens that the other group members contribute to the group account. You will enter your estimate as two integers: one number for the lower end of the range and another for the higher end of the range.

In Phase 2 of Part I, all group members will decide how much to actually contribute to the group account. We will round the actual average contribution of the other group members to the nearest integer, and compare it to the range you specified. You will earn ECU only if the actual (rounded) average contribution of others to the group account lies inside the range you specify. Furthermore, the wider the range you indicate the smaller are your potential earnings. More precisely, the exact amount you earn is calculated according to the following rules:

- If the actual (rounded) average lies outside of the range you specify you earn 0 ECU.

- The maximum you can earn is 20 ECU. You earn 20 ECU if you (a) specify only a single value - that is, if the lower number and the higher number you specify are the same - and (b) this value is equal to the actual (rounded) average contribution of others to the group account. So, for example, if you are certain that the average contribution of others will be 15 then you should enter 15 for both the lower number and the higher number. If the (rounded) average of others is actually 15 you will earn 20 ECU.

- As the range you specify becomes wider, you earn less money for a correct estimate. Specifically, for every unit that your range increases in width, your potential income decreases by 1 ECU. So, for example, if you enter 8 for the lower and 20 for the higher end of the range (i.e. your range has a width of 12) and the actual (rounded) average contribution of others is 14 tokens, then you will earn 20-12=8 ECU. You earn more than you would earn if you had entered a wider range, say from 5 to 20 (income $20-15=5 \mathrm{ECU}$ ), but you earn less than you would earn if you had entered a narrower range, say from 10 to 15 (income $20-5=15 \mathrm{ECU}$ ) or if you had entered a range consisting only of 14 (income $=20-0=20 \mathrm{ECU}$ ).

If you enter 0 for the lower end and 20 for the higher end, your range covers all possible average token amounts and the actual (rounded) average of others' contributions is thus guaranteed to lie in your range. In this case, you earn nothing (income $=20-20=0 \mathrm{ECU}$ ).

To summarize, the rule is that you earn money for specifying a range that contains the actual average of others' contributions,, but the amount you earn for such a correct estimate is smaller the wider the range you indicate. 


\section{b) Phase 2: "Unconditional contribution" and "contribution table"}

In the second phase of Part I, you will decide about your actual contribution to the group account. You have 20 tokens and you can choose to contribute any of these tokens to a group account. The tokens you do not contribute are put into your private account.

In this phase, you will make two types of contribution decisions: an unconditional contribution decision and a decision through a contribution table. Only one of these decisions will count, but you will not know which one until the end of the experiment. This means that you should treat each one as if it is the one that determines your earnings from Phase 2.

- In the unconditional contribution decision, you decide how many of the 20 tokens you contribute to the group account. You will enter your contribution decision as a single number between 0 and 20 .

- In the decision through a contribution table you may contribute different amounts for each possible average unconditional contribution of the other group members (rounded to the nearest integer). That is, you have to specify how much you want to contribute if the other three group members contribute, on average, 0 tokens, 1 token, 2 tokens, etc., up to 20 tokens, to the group account. You will see a table, with all 21 possible integer values from 0 to 20 , corresponding to the possible average unconditional contributions made by the other three group members.

\section{Earnings from Part I}

After all four participants in a group have made both types of decisions in Phase 2, your earnings from Part I will be determined as follows.

- First, the computer will compare the range you provided as an estimate for the other group members' average contributions to their actual average unconditional contributions. This will determine your earnings from Phase 1.

- Second, the computer will randomly select three group members to have their unconditional contributions count as their contribution decision. The computer will then calculate the average unconditional contribution of the three selected group members. This average determines how much the remaining group member will contribute, based on how that group member completed the contribution table. Together this determines the actual contributions of all four group members and, thus, each member's earnings from Phase 2. 
EXAMPLE: Assume that the three group members that were randomly selected to have their unconditional contributions count decided to contribute 0,3 , and 15 tokens. The average contribution of these three group members, therefore, is $18 / 3=6$ tokens. The computer will then check the contribution table of the remaining group member, for the entry in the row corresponding to an average contribution of 6 , and will use this entry to determine the contribution decision of this fourth group member. Suppose that this group member decided to contribute 10 when the average contribution by other group members is 6. Then, the computer will make this group member contribute 10. The total sum of contributions to the group account is thus $0+3+15+10=28$ tokens. All group members, therefore, earn $0.5 *$ $28=14$ ECU from the group account plus their respective incomes from the private accounts.

You will make these decisions only once in Part I. You will be informed about the contribution decisions of the other group members and your payoff from Part I at the end of the experiment, after everyone has made all decisions in the experiment.

Do you have any questions? If yes, please raise your hand. We will then come to you at your workplace. If not, please click "Continue" on your computer screen.

Once we have answered all questions, we will ask you to answer some comprehension questions on your computer screen. These questions will ensure that everyone understands the instructions for Part I. 


\section{B.2 Decision screens for Part I}

PART I
Phase 1: Beliefs about other group members' average contributions.

Please indicate in the boxes below the range in which you believe the (rounded) average contribution of the other group members will lie.

I believe that the other 3 group members will contribute on average

\section{at least:}

at most:

When you are ready to proceed, please click "Confirm".

Figure B.1: Beliefs about others' contributions.

You earn nothing if the actual (rounded) average contribution lies outside of the range that you provide

Your potential income decreases with the width of the range that you provide.

PART I

Phase 2: Unconditional contribution

Please indicate your unconditional contribution to the group account.

My unconditional contribution to the group account is:

When you are ready to proceed, please click "Confirm".

Note

You have an endowment of 20 tokens. You can contribute any integer amount between 0 and 20 tokens.

The tokens that you do not contribute to the group account will be put in your private account.

Figure B.2: Unconditional contribution decision. 
PART I

Phase 2: Contribution table

Please indicate your contribution to the group account given each possible (rounded) average contribution of the other group members.

My contribution to the group account is:
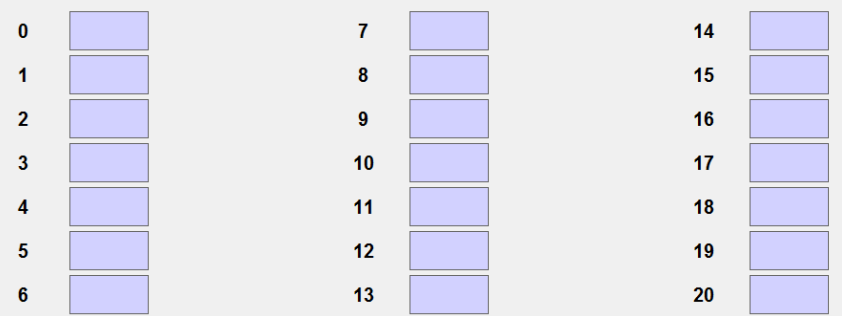

When you are ready to proceed, please click "Confirm". Please insert into each box the amount that you want to contribute to the group account if your group members contribute, on average, the (rounded) amount to the left of the box.

Figure B.3: Conditional contribution decision. 


\section{B.3 Instructions for Part II - "Endogenous institution" treatment}

\section{Part II}

\section{Group membership}

At the beginning of Part II, the computer will assign you at random to a group consisting of four participants that you have not interacted with before. This part of the experiment consists of 20 periods and all interactions during Part II take place with the same group members. In each period, you will simultaneously participate in two tasks. They will be displayed next to each other on the same computer screen and we will, thus, refer to these as Task Left and Task Right.

For each task, you have a separate endowment of 20 tokens that you can contribute to a group account or put in your private account, similar to the basic task in Part I. In Part II, everyone will make unconditional contributions. You will enter, separately, the number of tokens you decide to contribute to the group account in Task Left and in Task Right.

\section{Task Left}

On the left side of the computer screen, you will decide how many of your endowment of 20 tokens to contribute to the group account and how many to put in your private account. You can enter any integer from 0 to 20 . Your income from Task Left is calculated in the same way as described for the basic task and, thus, depends on your contribution and the contributions of the other three members of your group.

\section{Task Right}

On the right side of the computer screen, your group will, at the beginning of each period (and thus before a decision in Task Left can be made), first vote on a "contribution threshold." The contribution threshold specifies a minimum level of contribution to the group account in Task Right for each group member. The contribution threshold can be any value between 0 and 20 .

The contribution threshold affects the income of group members from Task Right, depending on whether they contribute at least as many or fewer tokens to the group account than specified by the contribution threshold. Specifically:

- The income from Task Right of any group member who contributes at least as many tokens to the group account as specified by the contribution threshold is not affected by the contribution threshold. The income from Task Right is then determined as described for the basic task. 
- Any group member who contributes fewer tokens to the group account than the minimum level specified by the contribution threshold loses any income from Task Right. That is, a group member that contributes less than the contribution threshold receives an income of 0 for Task Right, regardless of how much this group member or other group members contributed. Thus, there is a penalty for contributing fewer tokens to the group account than the contribution threshold, and the penalty is the loss of all income for that period in Task Right. A participant's income in Task Left is not affected by anything that happens in Task Right and vice versa. Similarly, if one participant is penalized for contributing less than the contribution threshold in Task Right, the incomes of other participants are not affected. Thus, the other group members still benefit from any contributions made by any group member in Task Right.

EXAMPLE: The contribution threshold is set to 15 in Task Right. Group member A contributes 5, member B 15, member C 20, and member D 20 tokens to the group account in Task Right. The total contributions are thus 60 tokens. Member A earns 0 ECU from Task Right, because he contributed less than the "contribution threshold" of 15 tokens. Member $B$ earns 5 ECU from the private account plus an income of $0.5 * 60=30$ ECU from the group account from Task Right. Member $C$ and Member D earn 0 ECU from the private account plus 30 ECU from the group account in Task Right. Note that all group members also earn money based on what happens in Task Left, which is independent of Task Right.

\section{How the contribution threshold for Task Right is determined:}

At the beginning of every period, before any contribution decisions are made, all four members of a group vote on the contribution threshold for Task Right for that period. Every member votes for a desired contribution threshold, by specifying an integer value between 0 and 20 .

The implemented contribution threshold for Task Right for that period is the lowest value voted for by any group member.

EXAMPLE: Assume that group member A votes for 7, group member B for 12, group member $C$ for 18, and group member D for 10. The implemented contribution threshold for Task Right in that period is 7, the lowest vote in the group. Any group member who contributes less than 7 tokens in that period in Task Right then earns 0 ECU from Task Right.

After the voting takes place, all group members are informed about the implemented contribution threshold and about all of the separate votes cast by members of the group. The votes will be presented in descending order and it is not possible to identify which member of the group voted for which value of the contribution threshold. 
Before you make your contribution decisions in Task Left and Task Right, we will ask you about your belief about the other group members' average contribution in Task Left and Task Right. Contrary to Part I, you will enter your (rounded) belief as a single number. So, for example, if you believe that the (rounded) average contribution is 12 in Task Left and 8 in Task Right, you should enter the numbers 12 and 8 in the respective input boxes on the screen. Whether your beliefs are correct or not does not impact your payoff. Please enter your best estimates.

After that you will make your contribution decisions in Task Left and Task Right.

\section{Summary}

You will make the following decisions in Part II:

- You will vote on a contribution threshold for Task Right. The contribution threshold changes the potential payoffs only in Task Right. It has no effect on the payoffs from Task Left.

- You will enter your beliefs about the average contribution of the other group members in Task Left and Task Right.

- You will then make two contribution decisions, one in Task Left and one in Task Right.

\section{Total income in each period}

Your total income in each period is equal to the sum of your incomes in the two tasks. So, for example, if you earn 30 ECU from Task Left and 10 ECU from Task Right, your total income in that period will be $40 \mathrm{ECU}$. At the end of each period all group members will be informed about their incomes in Task Left and Task Right and the respective contributions of all group members. The contributions will be presented in descending order and it is not possible to identify which member of the group contributed which number of tokens to the group accounts in Task Left and Task Right.

\section{Earnings from Part II}

At the end of the experiment, one out of the twenty periods from Part II will be randomly selected to count for payment. Your decisions and those of your group members in that period will then be implemented and will determine your earnings from Part II. Specifically, your payoff for the randomly selected period will be multiplied by 20 , so that it counts for all 20 periods. Note that every decision in each of the twenty periods can be relevant for your payoff. It is therefore important that you make your decisions in every period as if it would be the period that determines your actual payoff.

Do you have any questions? If yes, please raise your hand. We will then come to you at your workplace. Once we have answered all questions, we will ask you to answer some comprehension questions on your computer screen. These questions will ensure that everyone understands the instructions for Part II. 


\section{B.4 Decision screens for Part II - "Endogenous institution" treatment}

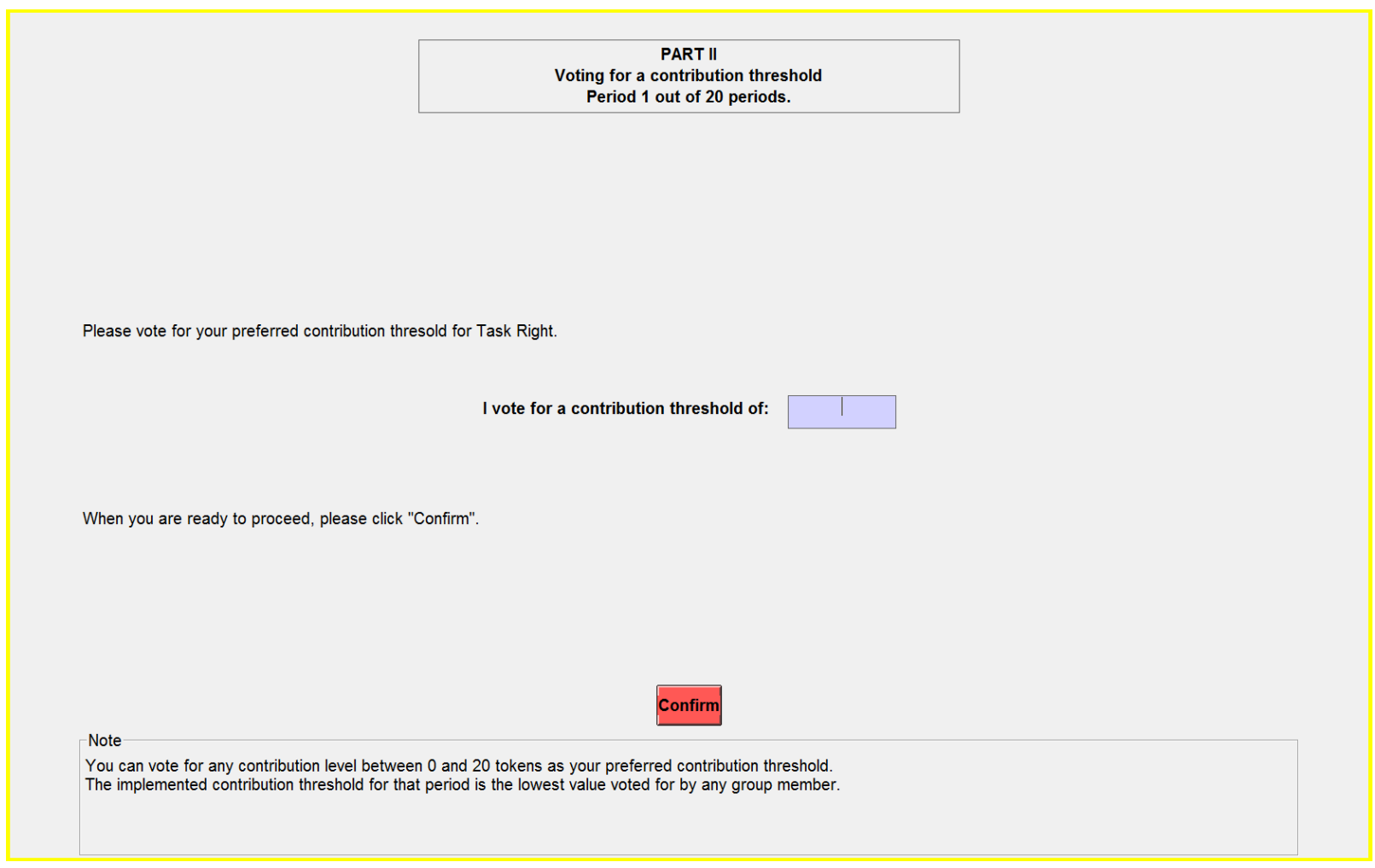

Figure B.4: Voting decision.

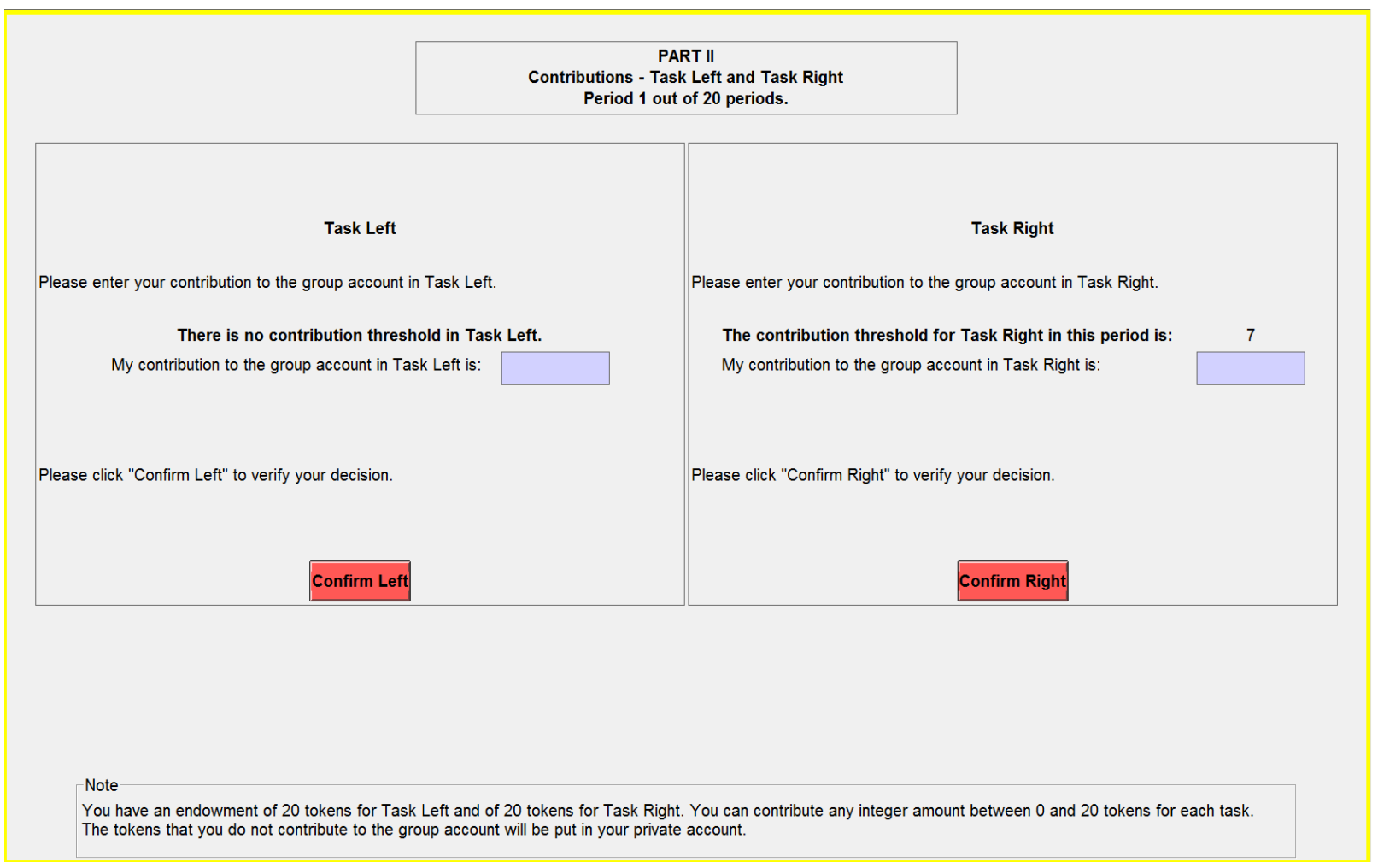

Figure B.5: Contribution decision for "PGG No Rule" and "PGG Rule". 